OPEN ACCESS

Edited by:

Sophie Molholm,

Albert Einstein College of Medicine,

USA

Reviewed by:

Robert Hester

University of Melbourne, Australia

Ryan Patrick Bell,

University of North Carolina - Chapel

Hill, USA

Kristen Paula Morie

Yale University, USA

*Correspondence:

Brendan M. Caldwell

bcaldwel/@mrn.org

Received: 15 June 2015 Accepted: 28 September 2015

Published: 16 October 2015

Citation:

Caldwell BM, Harenski $C L$, Harenski KA, Fede SJ, Steele VR, Koenigs MR and Kiehl KA (2015) Abnormal frontostriatal activity in recently abstinent cocaine users during implicit moral processing

Front. Hum. Neurosci. 9:565. doi: 10.3389/fnhum.2015.00565

\section{Abnormal frontostriatal activity in recently abstinent cocaine users during implicit moral processing}

\author{
Brendan M. Caldwell ${ }^{1 *}$, Carla L. Harenski ${ }^{1}$, Keith A. Harenski ${ }^{1}$, Samantha J. Fede ${ }^{1,2}$, \\ Vaughn R. Steele ${ }^{3}$, Michael R. Koenigs ${ }^{4}$ and Kent A. Kiehl ${ }^{1,2}$ \\ ${ }^{1}$ The Mind Research Network and Lovelace Biomedical and Environmental Research Institute, Albuquerque, NM, USA, \\ ${ }^{2}$ Department of Psychology, University of New Mexico, Albuquerque, NM, USA, ${ }^{3}$ Intramural Research Program, \\ Neuroimaging Research Branch, National Institute of Drug Abuse, National Institutes of Health, Baltimore, MD, USA, \\ ${ }^{4}$ Department of Psychiatry, University of Wisconsin-Madison, Madison, WI, USA
}

Investigations into the neurobiology of moral cognition are often done by examining clinical populations characterized by diminished moral emotions and a proclivity toward immoral behavior. Psychopathy is the most common disorder studied for this purpose. Although cocaine abuse is highly co-morbid with psychopathy and cocaine-dependent individuals exhibit many of the same abnormalities in socio-affective processing as psychopaths, this population has received relatively little attention in moral psychology. To address this issue, the authors used functional magnetic resonance imaging (fMRI) to record hemodynamic activity in 306 incarcerated male adults, stratified into regular cocaine users $(n=87)$ and a matched sample of non-cocaine users $(n=87)$, while viewing pictures that did or did not depict immoral actions and determining whether each depicted scenario occurred indoors or outdoors. Consistent with expectations, cocaine users showed abnormal neural activity in several frontostriatial regions during implicit moral picture processing compared to their non-cocaine using peers. This included reduced moral/non-moral picture discrimination in the $\mathrm{VACC}$, vmPFC, IOFC, and left vSTR. Additionally, psychopathy was negatively correlated with activity in an overlapping region of the ACC and right lateralized VSTR. These results suggest that regular cocaine abuse may be associated with affective deficits which can impact relatively high-level processes like moral cognition.

Keywords: Cocaine, Moral Intuition, Social Cognition, fMRI, Psychopathy

\section{INTRODUCTION}

"Moral cognition" refers to a set of complex processes giving rise to, and including, an individuals' judgments about the moral status of a person or action in a particular scenario. Academic interest in this aspect of our social world has been longstanding, but recent decades have seen a rapid expansion of moral psychological research into a myriad of scientific disciplines. Cognitive neuroscience is one of the more recent members- employing newly emerging neuroimaging techniques to provide novel insights into the neural circuitry engaged by moral cognition.

Many differing theoretical perspectives on moral cognition have followed, but one aspect which is widely shared amongst them is the bifurcation of moral decision-making into two relatively distinct, though highly interdependent, processes. The first, which we will refer to as "moral 
intuition," consists of relatively automatic and reflexive operations through which an individual attends and responds to the morally-salient aspects of a given stimulus. "Moral deliberation," by contrast, denotes more deliberative and cognitively taxing processes (e.g., evaluating the moral appropriateness of stimuli and identifying morally appropriate actions; Harenski et al., 2010a). The precise nature and role of these two processes is controversial (Haidt, 2001; Pizarro and Bloom, 2003; Greene et al., 2004; Hauser, 2006), but it is widely assumed that both play a significant role in moral cognition. Studying these two processes in isolation has subsequently become a major focus in moral cognition research (for review see Hauser, 2006).

The primary way neuroimaging studies have begun to tease apart these processes is by subtle task manipulations. To date, the majority of neuroimaging studies have employed "explicit" moral judgment tasks, in which participants are shown morallysalient stimuli and asked to rate their moral appropriateness. Because performance of these tasks requires both attendance to and reflective consideration of the moral information presented, the resultant neural activity likely represents both moral intuition and deliberation. The brain regions most consistently activated during explicit moral judgment tasks include the ventromedial prefrontal cortex (vmPFC), dorsolateral prefrontal cortex (dlPFC), temporo-parietal junction (TPJ), cingulate cortices (ACC and PCC), and amygdala (Amyg; for review see Fumagalli and Priori, 2012).

In contrast, a minority of neuroimaging studies have utilized 'implicit' moral tasks, in which morally-salient stimuli are presented but explicit moral judgments are not required. Tasks of this sort are thought to maintain the reflexive, perceptual aspects of moral cognition while minimizing its deliberative components. These studies have generally identified the TPJ and PCC as being central to the earliest stages of moral cognition (Harenski and Hamann, 2006; Moll et al., 2007; Schiach-Borg et al., 2008; Harenski et al., 2010a; Decety and Cacioppo, 2012).

Over the past decade, researchers have begun examining the neurobiology of moral cognition in clinical populations characterized by diminished moral emotions (e.g., guilt, empathy) and a proclivity toward immoral behavior. Psychopathy is the most common disorder studied for this purpose-a personality disorder typified by a suite of interpersonal, affective, and behavioral characteristics including grandiosity, callousness, and lack of empathy (Cleckley, 1976; Hare, 2003; Hare and Neumann, 2008). Individuals at the high end of this spectrum are targeted because they demonstrate a marked moral insensitivity and are disproportionately responsible for repetitive crime and violence in society (Hart and Hare, 1989; Harris et al., 1991; Hemphill et al., 1998).

Substance abuse is, in many ways, comparable to psychopathy, but has received much less attention in moral psychology. Substance abuse and psychopathy are highly co-morbid (Smith and Newman, 1990; Walsh et al., 2007) and substance abusers have consistently shown social and affective deficits compared to healthy controls (Aguilar de Arcos et al., 2005; Verdejo-García et al., 2007; Fernández-Serrano et al., 2010; Volkow et al., 2011).
After cannabis, cocaine is the second most widely abused illicit drug in the United States, with an estimated 4.4 million users in the United States as of 2013 (NSDUH). Moreover, both current and former cocaine-dependent individuals exhibit many of the same abnormalities in socio-affective processing as psychopaths. Psychopaths exhibit significant deficits in affective empathy and facial affect recognition (for review see Brook et al., 2013). Cocaine abusers, both active and abstinent, show similar deficits in emotion recognition, with fear being the most consistently misidentified emotional expression (Foisy et al., 2005; Fox et al., 2007, 2011; Kemmis et al., 2007; Verdejo-García et al., 2007; Fernández-Serrano et al., 2010; Morgan and Marshall, 2013). Deficits in social cognition have been observed as well, with cocaine abusers exhibiting impaired empathy (Ferrari et al., 2014; Hulka et al., 2014; Preller et al., 2014).

Social, affective, and moral cognition are thought to be highly interrelated at the neural level (Young and Dungan, 2012). As such, the similarities in social and affective abnormalities between psychopaths and cocaine abusers may very well extend into the moral domain. Although researchers have only recently begun to examine moral cognition amongst current and former substance abusers, early results have supported this conclusion. Similar to psychopaths, polysubstance dependent individuals have been found to make more "utilitarian" moral judgments than healthy controls (Carmona-Perera et al., 2012; Kornreich et al., 2013). The only neuroimaging study comparing moral cognition in cocaine-dependent and non-dependent individuals found that cocaine-dependent individuals did show reduced activity in paralimbic structures such as the dorsal ACC, PAG, and anterior insula while making moral judgments (Verdejo-García et al., 2012).

The somatic marker theory of addiction (Verdejo-García and Bechara, 2009) is a promising framework for conceptualizing the relationship between substance abuse and social cognition. This model theorizes two distinct, though highly interdependent, neural systems which play a role in any sort of decision-making. The core structure of the "impulsive neural system" is the amygdala, which couples stimuli with their associated somatic state. That somatic state is generated by effector structures such as the hypothalamus, autonomic brainstem nuclei, ventral striatum, and periaqueductal gray. The core structure of the "reflective neural system" is the vmPFC, which integrates emotional information-generated by the insula and PCC-and cognitive information-generated by the dlPFC and hippocampus. Drug addiction is thought to be the result of a hyperactive impulsive system, which weakens the regulatory power of the reflective system.

Etiologically, this is likely the result of the abused drug "hijacking" the normal reward circuitry, leading to an overvaluation of the drug at a neurological level. Current and abstinent stimulant addicts have demonstrated exaggerated autonomic responses to cues related to the substances they abuse(d) and a muted response to all non-drug affective stimuli (e.g., cues related to food, sex, etc...; Aguilar de Arcos et al., 2005; Asensio et al., 2010; Kim et al., 2011b). Blunted positive responses to pro-social interactions and blunted negative responses to socially aversive experiences could account for the deficits in 
social cognition and deleterious social behavior of stimulantdependent individuals (Volkow et al., 2011). Indeed, a few studies have found that the emotional and decision-making deficits seen in cocaine-dependent individuals are linked to the real-world social dysfunction of addicts (Cunha et al., 2011; Preller et al., 2014).

The extant neuroimaging studies on social and moral cognition in cocaine abusers have two notable limitations. First, none of these studies have examined moral intuition amongst cocaine abusers. Many real-world moral evaluations occur spontaneously upon the presentation of a morally salient social situation. An examination of moral intuition specifically may therefore provide us with a more ecologically rounded assessment of moral cognition. Secondly, none of these substance abuse studies examined the potential impact of comorbid psychopathy. The overlapping prevalence and associated neuropsychological deficits exhibited by these two disorders suggests that they may confound one another.

Here we used functional magnetic resonance imaging (fMRI) to evaluate brain activity during the performance of a moral intuitive processing task by individuals with varying levels of psychopathy and (past) cocaine use. Using the Mind Research Network's mobile MRI system, incarcerated participants were scanned while viewing pictures that did or did not contain moral violations (e.g., a hand breaking into a house vs. a mutilated hand), as well as affectively neutral pictures (e.g., a hand being fingerprinted), and judging whether each picture depicted a scene occurring indoors or outdoors. Participants were therefore exposed to morally salient stimuli, but were not made aware of the moral/non-moral picture distinction (Harenski et al., 2010a).

Integrating the findings of prior studies, we predicted that former cocaine users would exhibit reduced hemodynamic activity compared to non-cocaine users during the implicit processing of moral stimuli. Given the theorized etiology for such an effect, we predicted that abnormalities amongst cocaine users would be located in brain regions along the dopaminergic pathway normally used for reward processing-including the striatum, ACC and mPFC. Additionally, we hypothesized that cocaine users high in psychopathic traits would exhibit greater abnormalities in these areas compared to cocaine users lower in psychopathic traits.

\section{MATERIALS AND METHODS}

\section{Participants}

This study included 316 incarcerated male volunteers recruited from correctional facilities in New Mexico and Wisconsin. Inclusion criteria were: age between 18 and 50, reading level above 4th grade, IQ above 75, no history of seizures, no current Diagnostic and Statistical Manual of Mental Disorders (4th Edn.; American Psychiatric Association, 1994) Axis I diagnosis (excluding substance abuse), and no lifetime history of a psychotic disorder in self or first-degree relative. Incarcerated participants were in a controlled environment with restricted access to illicit drugs, and all reported to be abstinent from substance use for at least 1 month prior to testing. Ten incarcerated participants were excluded from analysis due to excessive motion during scanning. The final sample included 311 incarcerated participants. Incarcerated participants were included in the "Cocaine User" (CU) group if they had regularly used cocaine (three or more times per week) for any duration of time $(n=87)$. The remaining incarcerated participants were assigned to the Non-Cocaine Using (NCU) group $(n=$ 219). Additionally, a subset of the NCU group was matched with the CU group on age, IQ, psychopathy and severity of use for substances other than cocaine. This subset will be referred to as the Matched Non-Cocaine Users (mNCU). Demographic information on each group is provided in Table 1. Group comparisons on demographic variables between these three subsamples are provided in Table 2.

In order to generate task-specific ROIs, fMRI data was analyzed from a separate sample of 36 non-incarcerated male volunteers. Non-incarcerated participants were held to the same inclusion criteria, with the additional requirement that nonincarcerated participants be excluded if they had any history of an alcohol or drug use disorder.

\section{Assessments}

Psychopathy was assessed in all incarcerated participants using the Hare Psychopathy Checklist-Revised (PCL-R; Hare, 2003), which is a reliable and valid instrument for assessing psychopathy in incarcerated populations (Hare, 1980, 1996; Hart and Hare, 1989; Fulero, 1996). Trained researchers conducted semi-structured interviews covering topics such as school, employment, relationships, family, and criminal activity. Interview information was also corroborated by a review of the participant's institutional records. The PCL-R contains 20 items designed to measure the personality and behavioral characteristics of psychopathy. Each of these items is scored on a 3-point scale and total scores range from 0 to 40 . Factor analyses of the PCL-R have suggested that its items load onto two correlated factors. Factor 1 contains items having to do with the affective/interpersonal features of psychopathy, while Factor 2 consists of those features of psychopathy associated with an impulsive, antisocial, and unstable lifestyle (Hare, 2003).

All participants completed the Structured Clinical Interview for DSM-IV Disorders (SCID; First et al., 2002) with a trained research assistant, to assess past and present Axis I and II disorders. This included the drug use disorder screening questionnaire and module, which were used to evaluate alcohol and drug disorder histories for exclusion purposes (nonincarcerated participants) and identify prior substance use disorders for data analysis (incarcerated participants). Over 80\% of incarcerated participants met criteria for a past substance use disorder, accounting for the majority of past Axis I disorders in the sample (see Table S1 for a breakdown of SCID diagnoses).

Drug use history was collected using a modified version of the Addiction Severity Index (ASI; Mclellan et al., 1992). This assessment asked participants about their past use of alcohol, heroin, other opiates, cocaine, cannabis, methamphetamine, other amphetamines, and nicotine. For each of these substances, participants were asked if they ever used that substance three or 
TABLE 1 | Demographic information of incarcerated cocaine users and non-cocaine users.

\begin{tabular}{|c|c|c|c|c|c|c|}
\hline \multirow[t]{2}{*}{ Variable } & \multicolumn{2}{|c|}{$\operatorname{NCU}(n=219)$} & \multicolumn{2}{|c|}{$C U(n=87)$} & \multicolumn{2}{|c|}{$m N C U(n=87)$} \\
\hline & Mean & $S D$ & Mean & $S D$ & Mean & $S D$ \\
\hline Age & 32.15 & 8.07 & 34.9 & 8.08 & 33.59 & 8.90 \\
\hline IQ & 98.66 & 13.66 & 100.62 & 13.09 & 99.34 & 13.27 \\
\hline \multicolumn{7}{|l|}{ PSYCHOPATHY } \\
\hline PCLR Total & 22.265 & 7.4594 & 24.34 & 6.11 & 23.31 & 7.82 \\
\hline PCLR Factor 1 & 8.037 & 3.7866 & 8.05 & 3.73 & 8.05 & 3.99 \\
\hline PCLR Factor 2 & 12.186 & 4.2716 & 13.86 & 3.13 & 13.04 & 4.29 \\
\hline \multicolumn{7}{|l|}{ SUBSTANCE USE HISTORY } \\
\hline Alcohol & 0.105 & 0.148 & 0.205 & 0.195 & 0.17 & 0.18 \\
\hline Cannabis & 0.199 & 0.198 & 0.351 & 0.208 & 0.31 & 0.21 \\
\hline Heroin & 0.061 & 0.054 & 0.122 & 0.105 & 0.02 & 0.09 \\
\hline Other Opiates & 0.018 & 0.067 & 0.056 & 0.101 & 0.03 & 0.09 \\
\hline Cocaine & 0.000 & 0.000 & 0.136 & 0.141 & 0.00 & 0.00 \\
\hline Methamphetamine & 0.007 & 0.043 & 0.051 & 0.128 & 0.01 & 0.07 \\
\hline Other Amphetamines & 0.007 & 0.034 & 0.026 & 0.095 & 0.01 & 0.05 \\
\hline \multirow[t]{2}{*}{ Nicotine } & 0.248 & 0.223 & 0.408 & 0.194 & 0.36 & 0.23 \\
\hline & $N$ & $\%$ & $N$ & $\%$ & $N$ & $\%$ \\
\hline \multicolumn{7}{|l|}{ RACE } \\
\hline American Indian/Alaskan Native & 12 & 5.5 & 0 & 0 & 7 & 8 \\
\hline Asian & 1 & 0.5 & 0 & 0 & 1 & 1.1 \\
\hline Black & 73 & 33.3 & 13 & 14.9 & 27 & 31 \\
\hline Native Hawaiian/Pacific Islander & 3 & 1.4 & 0 & 0 & 0 & 0 \\
\hline White & 111 & 50.7 & 59 & 67.8 & 44 & 50.6 \\
\hline Other/Decline & 19 & 8.7 & 15 & 17.2 & 8 & 9.2 \\
\hline \multicolumn{7}{|l|}{ ETHNICITY } \\
\hline Not Hispanic & 193 & 88.1 & 64 & 73.6 & 77 & 88.5 \\
\hline Hispanic & 26 & 11.9 & 23 & 26.4 & 10 & 11.5 \\
\hline \multicolumn{7}{|l|}{ HANDEDNESS } \\
\hline Right & 184 & 84 & 78 & 89.7 & 73 & 83.9 \\
\hline Left & 26 & 11.9 & 7 & 8 & 11 & 12.6 \\
\hline Ambidextrous & 9 & 41 & 2 & 2.3 & 3 & 3.4 \\
\hline
\end{tabular}

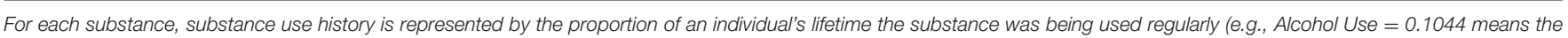
participant used alcohol regularly for $10.44 \%$ of his life).

more times per week and for how long they used the substance at least that often. To compensate for age as a confounding variable, severity of use for each substance was calculated by dividing the number of months of regular use by the age of the participant at the time of the interview. Abstinence information was collected in two different ways (see Supplementary Materials for additional information). Seventy-seven of the 306 incarcerated participants were simply asked how much of the substance in question they had used within the past 30 days. Those who reported no use were coded as "abstinent" for that substance. The remaining 229 incarcerated participants were asked to give an approximate date for the last time they had used the substance in question. For this sample, duration of abstinence was set by calculating the number of months between their last reported use and the date at which the assessment was administered (see Table S2 for additional substance use information).
The Balanced Inventory of Desired Responding (BIDR) was administered in order to gauge the accuracy of other self-report measures. The BIDR (Paulhus, 1984) is a 40 item inventory using a 7-point Likert scale consisting of two subscales: SelfDeception and Impression Management. The Self Deception scale is designed to assess defensiveness toward personal threats and positively biased responding that the respondent believes to be true (e.g., "I am a completely rational person"). The Impression Management scale is designed to measure responding that is guided by a desire to create a favorable impression on others (e.g., "I never take things that don't belong to me").

IQ was estimated using the Vocabulary and Matrix Reasoning subtests of the Wechsler Adult Intelligence Scale (WAIS; Wechsler, 1997; Ryan et al., 1999). Written informed consent was obtained from all participants, after a complete description of the study procedures. The study was reviewed and approved by the 
TABLE 2 | Group comparisons of demographic information for incarcerated cocaine users and non-cocaine users.

\begin{tabular}{|c|c|c|c|c|c|c|}
\hline \multirow[t]{2}{*}{ Variable } & \multicolumn{3}{|c|}{$C U$ vs. $N C U$} & \multicolumn{3}{|c|}{$C U$ vs. $m N C U$} \\
\hline & $t$ & $d f$ & $p$ & $t$ & $d f$ & $p$ \\
\hline Age & 2.69 & 304 & 0.008 & 1.02 & 172 & 0.312 \\
\hline IQ & 1.15 & 304 & 0.252 & 0.64 & 172 & 0.523 \\
\hline \multicolumn{7}{|l|}{ PSYCHOPATHY } \\
\hline PCLR Total & 2.51 & 191.4 & 0.013 & 0.97 & 163 & 0.336 \\
\hline PCLR Factor 1 & 0.02 & 304 & 0.984 & 0.00 & 172 & 1.000 \\
\hline PCLR Factor 2 & 3.74 & 217.33 & 0.000 & 1.42 & 152 & 0.158 \\
\hline \multicolumn{7}{|l|}{ SUBSTANCE USE HISTORY } \\
\hline Alcohol & 4.34 & 127.44 & 0.000 & 1.16 & 172 & 0.246 \\
\hline Cannabis & 5.98 & 304 & 0.000 & 1.60 & 172 & 0.112 \\
\hline Heroin & 3.02 & 107.90 & 0.003 & 1.45 & 169 & 0.150 \\
\hline Other Opiates & 3.24 & 116.88 & 0.002 & 1.43 & 172 & 0.155 \\
\hline Cocaine & 9.00 & 86 & 0.000 & 9.12 & 172 & 0.000 \\
\hline Methamphetamine & 3.14 & 93.791 & 0.002 & 2.37 & 172 & 0.019 \\
\hline Other Amphetamines & 1.82 & 94.704 & 0.073 & 1.08 & 172 & 0.283 \\
\hline \multirow[t]{2}{*}{ Nicotine } & 6.22 & 180.47 & 0.000 & 1.62 & 172 & 0.107 \\
\hline & $x^{2}$ & $d f$ & $p$ & $x^{2}$ & $d f$ & $p$ \\
\hline Race & 21.25001 & 5 & 0.001 & 17.2149 & 4 & 0.002 \\
\hline Ethnicity & 9.82098 & 1 & 0.002 & 6.319794 & 1 & 0.012 \\
\hline Handedness & 1.644219 & 2 & 0.440 & 1.25 & 2 & 0.534 \\
\hline
\end{tabular}

For each substance, substance use history is represented by the proportion of an individual's lifetime the substance was being used regularly.

University of New Mexico Human Research Review Committee. Participants received monetary compensation for participation. Incarcerated participants were paid at a rate commensurate to work assignments at their facility.

\section{Stimuli and Task}

Three sets of pictures (25 moral, 25 non-moral, 25 neutral) were selected, largely from the International Affective Picture System (IAPS; Lang et al., 1995), and supplemented with pictures from media sources. Each moral picture depicted an unpleasant social scene which included a moral violation (e.g., one person attacking another). Non-moral pictures also showed unpleasant social scenes, but they did not contain moral content (e.g., two individuals arguing). Neutral pictures depicted social scenes which were both affectively neutral and devoid of moral content (e.g., two individuals having a conversation). Moral and nonmoral pictures were selected based on ratings from a pilot study in which participants rated 100 unpleasant pictures on the moral status of the action depicted. Pictures which were rated highest and lowest on moral violation severity were assigned to the moral and non-moral conditions, respectively. Moral and nonmoral pictures were also matched on emotional arousal and social complexity, and neutral pictures were matched to moral and nonmoral pictures for social complexity. Within studies in which moral violation severity ratings were collected, the pictures in the moral subset have consistently been rated significantly higher on moral violation severity than non-moral pictures (Harenski and Hamann, 2006; Harenski et al., 2010b).
Participants were told that they would see a series of pictures depicting various people and events. For each picture, they were instructed to determine whether the social scene shown was taking place indoors or outdoors. Participants were not informed of the moral/non-moral distinction across pictures. After being given these instructions, participants completed at least five practice trials in the scanner to ensure that they understood how to perform the task. For each trial, a picture from one of the three sets was displayed on screen for $6 \mathrm{~s}$. Then, participants were presented with a screen reading "Indoor/Outdoor?" and given $4 \mathrm{~s}$ to indicate their answer. They were instructed to press one button with their index finger if the picture occurred indoors, and a different button with their middle finger if the picture occurred outdoors. Each of the three picture conditions contained the same proportion of indoor and outdoor pictures (44/56\%).

Moral, non-moral, and neutral picture trials were presented in a random order and interspersed with 25 null trials in which a fixation cross was presented for the entire trial. The 100 total trials were presented across two separate runs of the task. Images were rear-projected into the scanner using an LCD projector, controlled by a PC computer. Tasks were designed and presented and responses were recorded using Presentation software (Version 10.78, http://www.neurobs.com/).

\section{MRI Data Acquisition and Analysis}

MR images were collected using a mobile Siemens $1.5 \mathrm{~T}$ Avanto with advanced SQ gradients (max slew rate $200 \mathrm{~T} / \mathrm{m} / \mathrm{s}, 346 \mathrm{~T} / \mathrm{m} / \mathrm{s}$ vector summation, rise time $200 \mu \mathrm{s}$ ) equipped with a 12 -element 
head coil. The EPI gradient-echo pulse sequence (TR/TE $2000 / 39 \mathrm{~ms}$, flip angle $90^{\circ}$, FOV $24 \times 24 \mathrm{~cm}, 64 \times 64$ matrix, $3.4 \times 3.4 \mathrm{~mm}$ in-plane resolution, $5 \mathrm{~mm}$ slice thickness, 30 slices) effectively covered the entire brain $(150 \mathrm{~mm})$ in $2.0 \mathrm{~s}$. Head motion was minimized using padding and restraint.

To correct residual head motion, "bad" images (confounded by motion or radio-frequency spikes) were estimated and removed using ART-Repair (Mazaika et al., 2009). These images were determined by calculating the mean intensity for a given time series and identifying individual images whose intensity was greater than four standard deviations from the mean. The offending image(s) were replaced in the time series by a rolling mean image, and regressed in the statistical model. The mean number of images removed across participants was 1.98 (of 356).

Imaging data were analyzed using SPM5 (www.fil.ion.ucl.ac.uk/spm/software/spm5). Functional images were spatially normalized to the MNI template and smoothed (8 mm FWHM). Picture presentations (moral, non-moral, neutral) and the rating period for all pictures were modeled as four separate events. Each event was modeled with a six (picture) or four (indoor/outdoor judgment) second hemodynamic response function. Functional images were computed for each participant that represented brain activation associated with viewing moral, non-moral, or neutral pictures. The moral > non-moral picture comparison evaluated brain activation to morally-salient pictures while controlling for general emotional and social content.

The relationship between substance use and neural activity can be characterized by both the general effect of substance use, and by correlations between the severity of substance use and neural activity. Moreover, substance use disorders are generally conceptualized as taxa (DSM-5; ICD-10), although dimensional models have been proposed more recently (e.g., Muthén, 2006; Eaton et al., 2015; for review see Haslam et al., 2012). Consequently, the relationship between hemodynamic responses during the moral $>$ non-moral condition and cocaine use was analyzed in two stages. First, a two-sample $t$-test compared the $\mathrm{CU}$ group to the $\mathrm{mNCU}$ group. This comparison group was matched on age, IQ, psychopathy and severity of use and duration of abstinence for the following substances: alcohol, cannabis, heroin, other opiates, other amphetamines and nicotine. Second, severity of cocaine use was entered into a regression with individual moral $>$ non-moral contrast images only for CUs. Age, IQ, psychopathy and severity of use for alcohol, cannabis, heroin, other opiates, other amphetamines, and nicotine were also entered in as covariates into this regression. Only CUs were included in this regression analysis because severity of cocaine use was positively skewed within the full incarcerated sample ( kewness $=1.946$, kurtosis $=2.898$ ). To correct for skew within the CU sample, severity of cocaine use was calculated by taking the square root of the duration of regular use divided by the participant's age (Ermer et al., 2012).

Additionally, duration of abstinence from regular cocaine use was entered into a regression with individual moral > non-moral contrast images only for CUs who had abstinence information available $(n=61)$. Age, IQ, psychopathy, severity of use for cocaine, alcohol, cannabis, heroin, other opiates, other amphetamines and nicotine, and duration of abstinence for alcohol, cannabis, heroin, other opiates, other amphetamines and nicotine were also entered in as covariates into this regression (see Supplementary Materials for additional information). There were no significant group differences between CUs, mNCUs, or NCUs in the number of abstinent participants or the duration of abstinence for any substances (see Tables S2A-C).

Age and IQ scores were not significantly correlated with PCL$\mathrm{R}$ or Factor scores. Consistent with the extant literature, CUs were significantly higher on Factor 2 scores, but not on Factor 1, compared to the NCU sample (see Table 2). IQ was not significantly correlated with any cocaine use measures.

Analyses were performed on a voxel-by-voxel basis over the entire brain using the general linear model in SPM. Hypotheses were tested in regions of interest (PCC, vmPFC, ACC, vSTR, dlPFC). Peak coordinates for these regions were drawn from the moral $>$ non-moral functional maps of a separate sample of 36 non-incarcerated participants (see Table 3 for results). In all a priori regions of interest, family-wise error extent thresholds were small-volume corrected using $10 \mathrm{~mm}$ spheres surrounding the peak coordinate.

Whole-brain analyses were thresholded at $p<0.001$, and FWE corrected using cluster-extent based thresholding with primary threshold of $p<0.05$. Cluster thresholds for wholebrain family-wise error multiple comparison correction were derived from Monte Carlo simulations (3dClustSim, AFNI, http://afni.nimh.nih.gov). For the group comparison of CUs and mNCUs, the cluster threshold was set at $\geq 1026 \mathrm{~mm}^{3}$ (38 contiguous voxels). For the regression analysis within the entire incarcerated sample, the cluster threshold was set more stringently at $\geq 1134 \mathrm{~mm}^{3}$ (42 contiguous voxels).

\section{Imaging Results}

We first examined the main effects of viewing moral > non-moral pictures across all non-incarcerated participants (Figure 1). Consistent with a previous study employing this task in a non-clinical population, the main effect of moral vs. nonmoral pictures in the non-incarcerated sample revealed increased hemodynamic response in regions previously implicated in moral intuition (Harenski et al., 2010a) — including the bilateral temporo-parietal junction and posterior cingulate cortex. The main effect of moral vs. non-moral pictures in the nonincarcerated sample showed a similar pattern of results (see Table 3 for main effects).

Relative to matched non-cocaine users, cocaine users showed significantly reduced hemodynamic activity in the moral > non-moral contrast in several cortical and subcortical regions. Whole-brain analysis revealed reduced activity in both the left subgenual anterior cingulate cortex (sgACC) and right superior frontal gyrus (SFG). Small-volume correction revealed additional areas of hypoactivation. In the left hemisphere, these included the ventral and dorsal striatum (vSTR and dSTR), ventral anterior cingulate cortex (vACC), ventromedial prefrontal cortex (vmPFC), and middle temporal gyrus (MTG). On the right, hypoactivity was observed in the dorsomedial prefrontal cortex ( $\mathrm{dmPFC})$ extending into the rostral anterior cingulate cortex (rACC), and ventrolateral prefrontal cortex (vlPFC) 
TABLE 3 | Imaging results for healthy controls and full incarcerated sample.

\begin{tabular}{|c|c|c|c|c|c|c|c|c|c|c|c|c|c|}
\hline Region & $B A$ & $x$ & $y$ & $z$ & $t$ & $k$ & $p$ & $x$ & $y$ & $Z$ & $t$ & $k$ & $p$ \\
\hline L. TPJ & 39 & -48 & -60 & 30 & 5.05 & 594 & 0.000 & -51 & -60 & 27 & 13.53 & 7810 & 0.000 \\
\hline R. TPJ & 39 & 54 & -48 & 24 & 4.55 & 213 & 0.004 & 54 & -54 & 24 & 10.14 & & \\
\hline L. Fusiform & $19 / 37$ & -21 & -45 & -9 & 3.65 & 29 & 0.95 & -24 & -42 & -12 & 13.19 & & \\
\hline L. MTG & 21 & -48 & -18 & -18 & 3.49 & 16 & 0.998 & -57 & -21 & -12 & 8.09 & & \\
\hline L. MTG & 21 & -51 & -33 & -3 & 3.1 & 6 & 1 & -60 & -36 & -6 & 7.02 & & \\
\hline B. PCC & $23 / 31$ & 6 & -60 & 30 & 4.8 & 236 & 0.002 & 0 & -18 & 39 & 3.32 & 4 & 0.979 \\
\hline L. dmPFC & 9 & -9 & 60 & 33 & 4.13 & 118 & 0.076 & -3 & 48 & 36 & 9.39 & 3063 & 0.000 \\
\hline L. rostral ACC & 32 & 15 & 39 & 15 & 3.22 & 2 & 1 & -6 & 51 & 15 & 8.84 & & \\
\hline L. dIPFC & 8 & -42 & 15 & 54 & 3.91 & 24 & 0.981 & -48 & 15 & 45 & 8.4 & & \\
\hline R. dlPFC & 8 & 24 & 27 & 54 & 3.35 & 12 & 1 & 45 & 15 & 45 & 5.5 & 149 & 0.001 \\
\hline L. vmPFC & 47 & -33 & 21 & -21 & 3.79 & 22 & 0.988 & -30 & 21 & -15 & 4.95 & & \\
\hline L. vmPFC & 10 & -21 & 60 & 21 & 2.8 & 1 & 1 & -24 & 57 & 27 & 5.08 & & \\
\hline R. vmPFC & 10 & 3 & 57 & -9 & 2.77 & 1 & 1 & -3 & 57 & -9 & 6.42 & & \\
\hline L. VIPFC & $45 / 44$ & -54 & 21 & 18 & 3.62 & 12 & 1 & -57 & 21 & 15 & 5.91 & & \\
\hline R. vIPFC & 47 & & & & & & & 42 & 30 & -12 & 3.72 & 9 & 0.879 \\
\hline L. ventral ACC & 32 & -12 & 45 & 0 & 3.39 & 8 & 1 & -30 & 60 & 12 & 3.36 & 5 & 0.965 \\
\hline L. Putamen & 49 & -21 & 9 & 9 & 3.3 & 17 & 0.998 & -12 & 3 & 9 & 3.28 & 2 & 0.995 \\
\hline L. Temporal Pole & 38 & -51 & 6 & -33 & 2.98 & 2 & 1 & -39 & 18 & -33 & 3.19 & 1 & 0.998 \\
\hline R. Cerebellum & NA & 18 & -72 & -30 & 2.25 & 10 & 1 & 24 & -81 & -33 & 6.25 & 375 & 0.000 \\
\hline R. Thalamus & 50 & 18 & -15 & 0 & 2.65 & 19 & 1 & 15 & -21 & 9 & 3.89 & 4 & 0.979 \\
\hline
\end{tabular}

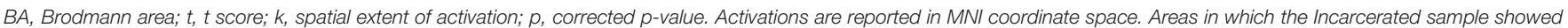

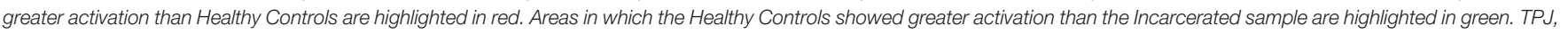

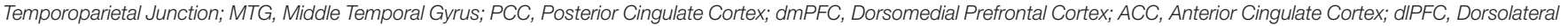
Prefrontal Cortex; vmPFC, Ventromedial Prefrontal Cortex; vIPFC, Ventrolateral Prefrontal Cortex.

extending into the anterior insula (aINS). Hypoactivation was observed bilaterally in the parahippocampal gyrus (PHG) and anterior thalamus (THAL). Cocaine users did not show greater hemodynamic activity in the moral > non-moral contrast, compared to the mNCUs, in any regions of interest (see Table 4).

Within the CU sample, no significant correlations were found between hemodynamic activity in the moral $>$ non-moral contrast and severity of cocaine use. Factor 1 scores, however, were negatively correlated with hemodynamic activity in the right vSTR and $\mathrm{rACC}$ in the moral $>$ non-moral contrast (see Table 5). For those in the CU sample with duration of abstinence information $(n=61)$, duration of abstinence from cocaine was negatively correlated with hemodynamic activity in the right posterior cingulate cortex (PCC) for the moral $>$ non-moral contrast (see Table 6).

\section{DISCUSSION}

The present study investigated whether cocaine abuse held any relationship to the neural systems underlying moral intuition, and what impact psychopathic traits might have on this relationship. Consistent with our hypothesis, individuals in the Cocaine Users group exhibited significantly reduced activation while viewing moral pictures relative to non-moral pictures in several cortico-limbic regions, compared to their non-cocaine using counterparts. In the left hemisphere, these included the ventral striatum (vSTR), subgenual cingulate cortex (sgACC), and ventromedial prefrontal cortex (vmPFC). On the right, hypoactivity was observed in the dorsomedial prefrontal cortex ( $\mathrm{dmPFC}$ ) extending into the pregenual anterior cingulate cortex (pgACC), and ventrolateral prefrontal cortex (vlPFC) extending into the anterior insula (aINS). Additionally, cocaine users higher in psychopathic traits exhibited additional neural abnormalities in the right vSTR and more severe aberration in the right pgACC.

CUs exhibited reduced activity in the left vSTR during moral vs. non-moral picture processing, when compared to mNCUs. Moreover, within the CU group, hemodynamic activity in the right vSTR was negatively correlated with Factor 1 scores. A plethora of research has established that this reward pathway is involved in the perception of social stimuli and social interaction (Skuse and Gallagher, 2009; Volkow et al., 2011; Lin et al., 2012), and is theorized to be crucially involved in motivating prosocial behavior (Moll et al., 2006; Izuma et al., 2010). During moral intuition, the vSTR may be partially responsible for the generation of a negative affective state associated with witnessing an immoral act. Although, commonly associated with positive feedback linked to reward, the vSTR has also been implicated in the generation of negative emotional states (Horvitz, 2000; Pruessner et al., 2004).

Functional abnormalities within the vSTR are consistent with our etiological account of cocaine's effect on social cognition. Acute administration of cocaine increases extracellular dopamine (DA) levels by blocking presynaptic dopamine transporter (DAT; Ritz et al., 1987). With regular use, compensatory changes begin to occur, such as downregulation of DA receptors, transporters, and function (Adinoff, 2004). Cocaine abusers have shown 


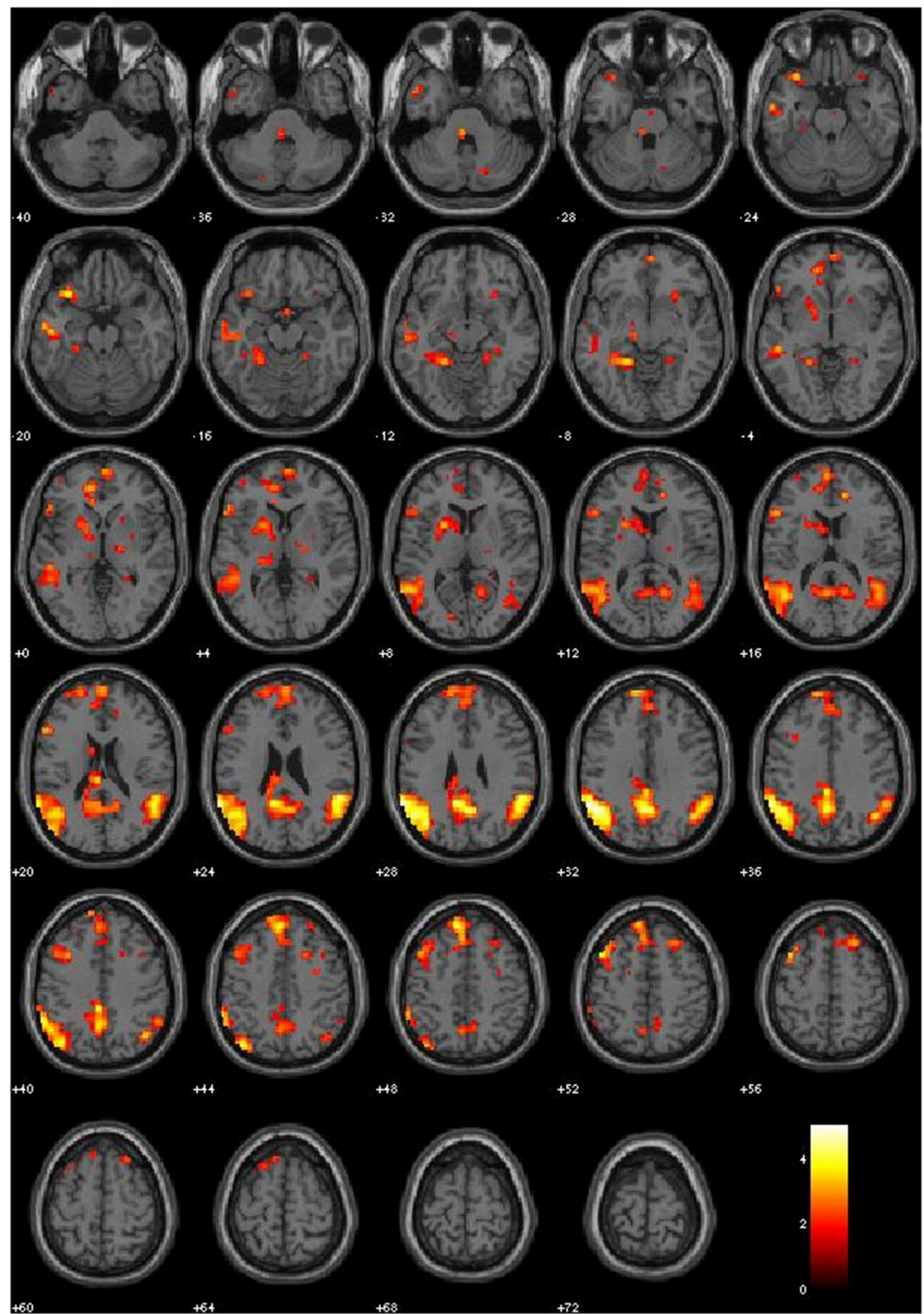

FIGURE 1 | Main Effect of Moral > Non-Moral condition in healthy controls ( $p$-threshold $=0.05$ ). 
TABLE 4 | Imaging results from group comparison of Cocaine Users (CU) and Matched Non-Cocaine Users (mNCU).

\begin{tabular}{|c|c|c|c|c|c|c|c|}
\hline \multicolumn{8}{|l|}{ Moral > Non-Moral } \\
\hline$m N C U>C U$ & $B A$ & $x$ & $y$ & $z$ & $t$ & $\boldsymbol{k}$ & $p$ \\
\hline L. subgenual ACC & $32 / 25$ & -6 & 21 & -3 & 4.62 & 52 & 0.056 \\
\hline R. Superior Frontal Gyrus & 10 & 24 & 48 & 12 & 4.88 & 39 & 0.134 \\
\hline R. Middle Frontal Gyrus* & $10 / 32$ & 21 & 45 & 12 & 4.04 & 64 & 0.004 \\
\hline R. Inferior Frontal Gyrus* & 47 & 33 & 24 & -18 & 3.25 & 33 & 0.044 \\
\hline L. Medial Frontal Gyrus* & 10 & -3 & 54 & -6 & 3.32 & 64 & 0.037 \\
\hline L. ventral $\mathrm{ACC}^{*}$ & $10 / 11 / 32$ & -9 & 42 & -6 & 4.05 & 98 & 0.004 \\
\hline R. Cuneus* & $19 / 18 / 17$ & 12 & -63 & 6 & 3.66 & 124 & 0.014 \\
\hline R. Precuneus* & 7 & 15 & -75 & 54 & 3.7 & 145 & 0.012 \\
\hline R. Parahippocampal Gyrus* & $19 / 36 / 37$ & 21 & -45 & -6 & 3.51 & 77 & 0.022 \\
\hline L. Middle Temporal Gyrus* & $21 / 37$ & -48 & -48 & -3 & 3.32 & 86 & 0.037 \\
\hline L. Parahippocampal Gyrus* & 36 & -18 & -42 & 0 & 3.62 & 41 & 0.016 \\
\hline L. Thalamus* & 50 & -9 & -3 & 6 & 3.26 & 81 & 0.043 \\
\hline R. Thalamus* & $50 / 48$ & 12 & -6 & 15 & 3.13 & 15 & 0.059 \\
\hline
\end{tabular}

$C U>m N C U$

None

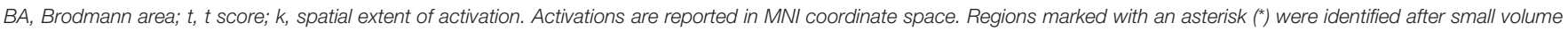

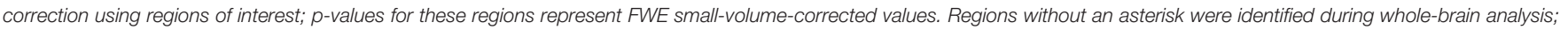
$p$-values for these regions are corrected $p$-values.

TABLE 5 | Imaging results from regression with psychopathy within the cocaine users group.

\begin{tabular}{|c|c|c|c|c|c|c|c|}
\hline \multicolumn{8}{|l|}{ Moral > Non-Moral } \\
\hline \multicolumn{8}{|l|}{ None } \\
\hline \multicolumn{8}{|l|}{ Negative Correlation } \\
\hline R. ventral Striatum & $52 / 48$ & 9 & 3 & -9 & 3.82 & 17 & 0.011 \\
\hline
\end{tabular}

Factor 2

None

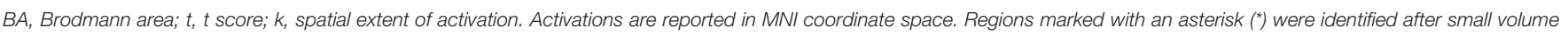

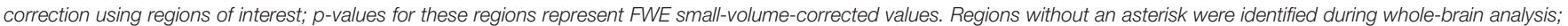
$p$-values for these regions are corrected $p$-values.

reductions in D2 receptor binding, extending into prolonged abstinence (Volkow et al., 1990), which may be associated with increased DA transporter availability (Bowers et al., 1998). One of the most common functional abnormalities exhibited by cocaine users is and over-reactivity to cocaine-related stimuli and under-reactivity to stimuli with any other contant (Aguilar de Arcos et al., 2005; Volkow et al., 2010), and this differential reactivity is generally associated with aberrant VSTR activity (Volkow et al., 2006; Childress et al., 2008; Asensio et al., 2010; Dunning et al., 2011; Holroyd et al., 2014). Our findings suggest that, in addition to being under-reactive to non-drug rewards, cocaine users may also be under-reactive to aversive stimuli which are unrelated to cocaine use, such as depictions of immoral acts.

As part of the mesocorticolimbic domapine pathway, the vSTR projects to many of the other brain regions in which CUs exhibited hypoactivity - including the mPFC, ACC and aINS (Haber, 2011). These areas also work collectively as part of the "visceromotor network" - which is thought to play a critical role in the identification of the emotional significance of environmental stimuli, the production of affective states, and automatic regulation of these autonomic responses to emotive stimuli via the production of visceral states (Phillips et al., 2003; Critchley, 2005; Lindquist et al., 2012). During social cognition, 
TABLE 6 | Imaging results from regression with duration of abstinence from cocaine within the cocaine users group.

\begin{tabular}{|c|c|c|c|c|c|c|c|}
\hline \multicolumn{8}{|l|}{ Moral > Non-Moral } \\
\hline Cocaine Abstinence & $B A$ & $x$ & $y$ & $z$ & $t$ & $\boldsymbol{k}$ & $p$ \\
\hline \multicolumn{8}{|l|}{ Positive Correlation } \\
\hline \multicolumn{8}{|l|}{ None } \\
\hline \multicolumn{8}{|l|}{ Negative Correlation } \\
\hline R. posterior Cingulate Cortex ${ }^{*}$ & 23 & 18 & -60 & 2 & 3.6 & 102 & 0.026 \\
\hline
\end{tabular}

this network is largely responsible for our tendency to reflexively embody the bodily states of observed agents- a process thought to be a central component of affective empathy (Decety and Jackson, 2004; Lamm et al., 2011; Zaki and Ochsner, 2012; Raz et al., 2014) and social cognition more generally (Vogt, 2005; Amodio and Frith, 2006).

Both moral and non-moral pictures have negatively valenced affective content insofar as they depict people who are suffering. Moral pictures, however, are distinct in that they depict a transgressor who is inflicting that suffering on a victim. This additional feature is likely to give moral stimuli additional affective salience- stemming from a reflexive appreciation of the affective state of the victim or an aversive response to the "wrongness" of the transgressor's behavior. Hypoactivity within this visceromotor network during moral vs. non-moral picture processing suggests that CUs are relatively insensitive to this difference in affective content. In other words, the neural abnormalities identified may be indicative of an aberration in the affective component of moral intuition in cocaine users.

In contrast to mNCUs, who recruited the left vmPFC more during moral compared to non-moral picture processing, CUs exhibited similar hemodynamic activity in this region across both types of stimuli. The vmPFC has been implicated in moral cognition across a myriad of studies (e.g., Greene et al., 2001; Moll et al., 2001, 2002a,b; Heekeren et al., 2003; Harenski and Hamann, 2006; Luo et al., 2006; Schiach-Borg et al., 2006; Prehn et al., 2007; Harenski et al., 2009; Young and Saxe, 2009; Shenhav and Greene, 2010; Sommer et al., 2010). Within healthy populations, the vmPFC is responsible for integrating emotional information into decision-making (Rolls, 2004; Bechara and Damasio, 2005; Lindquist et al., 2012) and is therefore thought to be involved in the affective aspects of moral cognition (Greene et al., 2001; Moll et al., 2002a,b; Heekeren et al., 2003). Individuals who have suffered damage to this area often exhibit impulsive and callous behavior (Rolls et al., 1994; Grafman et al., 1996; Brower and Price, 2001) along with abnormal moral cognition, which is generally interpreted to be the result of an emotional deficit (Ciaramelli et al., 2007; Koenigs et al., 2007; Moretto et al., 2010; Thomas et al., 2011). Increased activity during moral picture processing in the vmPFC may therefore be the result of a stronger affective reaction to the moral content of those stimuli. Correspondingly, similar recruitment of this region across both types of stimuli may be the result of a comparatively reduced affective response to moral stimuli.

Cocaine users showed a similar abnormal pattern of neural activity in two regions of the pgACC-one adjacent to the $\mathrm{dmPFC}$ (rACC) and the other adjacent to the vmPFC (vACC). In both these regions, mNCUs exhibited greater hemodynamic activity for moral vs. non-moral stimuli, while CUs did not. The pgACC is selectively engaged when task-irrelevant information interferes with performance due to its emotional content (Whalen et al., 1998; Haas et al., 2006; Mohanty et al., 2007; Egner et al., 2008; Ochsner et al., 2009; Etkin et al., 2011; Kanske and Kotz, 2011a,b; Iordan et al., 2013). The more dorsal portion of the pgACC helps resolve these emotional conflicts by inhibiting incongruent emotional reactions (Ochsner et al., 2004; Koenigs and Tranel, 2007; Diekhof et al., 2011; Amemori and Graybiel, 2012), possibly through a down-regulation of amygdalar activity (Etkin et al., 2006; Bissière et al., 2008). Importantly, however, the need for regulation does not appear to be necessary for pgACC activity. Several studies have found ACC activity in response to emotional stimuli even in contexts where attentional control was not required for performance (Pissiota et al., 2003; Kosson et al., 2006; Nakic et al., 2006; Chiu et al., 2008; Todd et al., 2014). It is likely, therefore, the pgACC is involved both in the identification of salient emotional information and the emotional conflict regulation.

Compared to mNCUs, CUs exhibited substantially less hemodynamic activity in the sgACC during moral relative to non-moral picture processing. Functionally, the sgACC has been consistently implicated in emotional processing (Cromheeke and Mueller, 2014). This area has strong projections to visceral and emotional control centers such as the amygdala and ventral striatum (Johansen-Berg et al., 2007; Vogt and Vogt, 2009) and is thought to play a crucial role in mood disorders marked by anhedonia (Greicius et al., 2007; Drevets et al., 2008). Recent research has also implicated the sgACC in socio-moral emotions such as guilt, a self-referential emotion generally elicited by the violation of moral norms (Zahn et al., 2009a; Green et al., 2010; Basile et al., 2011; Wagner et al., 2011), and empathic concern for the victims of harmful actions (Zahn et al., 2009b; Decety et al., 2012; Wiech et al., 2013). sgACC activity has also been implicated in the implicit processing of morally salient statements (Luo et al., 2006; Schiach-Borg et al., 2008). 
One noteworthy complication in this interpretation is that, unlike all the other regions of hypoactivity amongst the CUs, the pattern of results in the sgACC indicated similar deactivation in the moral and non-moral conditions for the NCUs and greater deactivation in the moral relative to non-moral condition for the cocaine users (see Figure 2). Given the purported role of the sgACC in empathic concern and the fact that both moral and non-moral stimuli depicted suffering, similar activation in this area between stimulus types might be expected. Conversely, however, this would imply that the cocaine users had less of an empathic response when the suffering was due to an immoral act than when it was not. Research on the role of the sgACC in social cognition, especially moral processing, is in its infancy. Future investigations may find that this region plays a much more complex part in moral cognition, and help to provide an explanation for this finding.

Lastly, it is worth noting that, within the Cocaine User group, no significant correlations were found between the severity of cocaine use and hemodynamic activity during moral picture processing. Many functional neuroimaging studies on substance use have found similar results. This discrepancy might be resolved with an improved measure for cocaine use severity. Additional information which may improve severity measures includes: the age(s) of the participant during regular use, the average quantity of cocaine used during periods of regular use and the duration of abstinence from cocaine use prior to scanning. Moreover, devising a substance use measure which applies to individuals who used a drug with some frequency, but fewer than three times a week, would help to normalize the distribution of that measure within the population.

Consistent with our second hypothesis regarding the interaction between psychopathy and cocaine abuse, within the cocaine users, higher Factor 1 scores were associated with reduced activity in the right vSTR and rACC. These regions have been implicated separately in both substance abuse and psychopathy research

Several studies have identified functional (Kiehl et al., 2001; Buckholtz et al., 2010; Bjork et al., 2012; Decety et al., 2013; Pujara et al., 2013) and structural (Glenn et al., 2010; Schiffer et al., 2011; Boccardi et al., 2013; Hoppenbrouwers et al., 2013) striatal abnormalities in individuals high in psychopathic traits. Individuals who are less empathic would be expected to have less of a negative affective reaction to witnessing someone else being wronged. Reduced vSTR activity while observing immoral acts in cocaine users who exhibit more of the interpersonal and affective psychopathic traits, is consistent with the purported role of this region in moral intuition.

Similarly, both cocaine users and psychopaths have demonstrated hypoactivity in the right rACC. Within psychopathy research, hypoactivity within the rACC has been associated with reduced allocation of attention toward the affective content of stimuli (Kiehl et al., 2001; Müller et al., 2003; Birbaumer et al., 2005). Several different etiological models of psychopathy have proposed an attention deficit as being central to the disorder (MacCoon et al., 2004; Hiatt and Newman, 2006; Kiehl, 2006). The paralimbic dysfunction model hypothesizes that the deficit is in emotional attention specifically-whereby psychopaths are under-reactive to affective information outside the current focus of attention (Kiehl, 2006). This hypothesis has been supported by a number of studies showing that psychopaths tend to perform better than average when the task containing emotional information that is incongruent with performance (Christianson et al., 1996; Mitchell et al., 2006) and worse when it is relevant (Williamson et al., 1991; Lorenz and Newman, 2002). However, the fact that this region was also found to be hypoactive in CUs compared to mNCU, who did not differ on

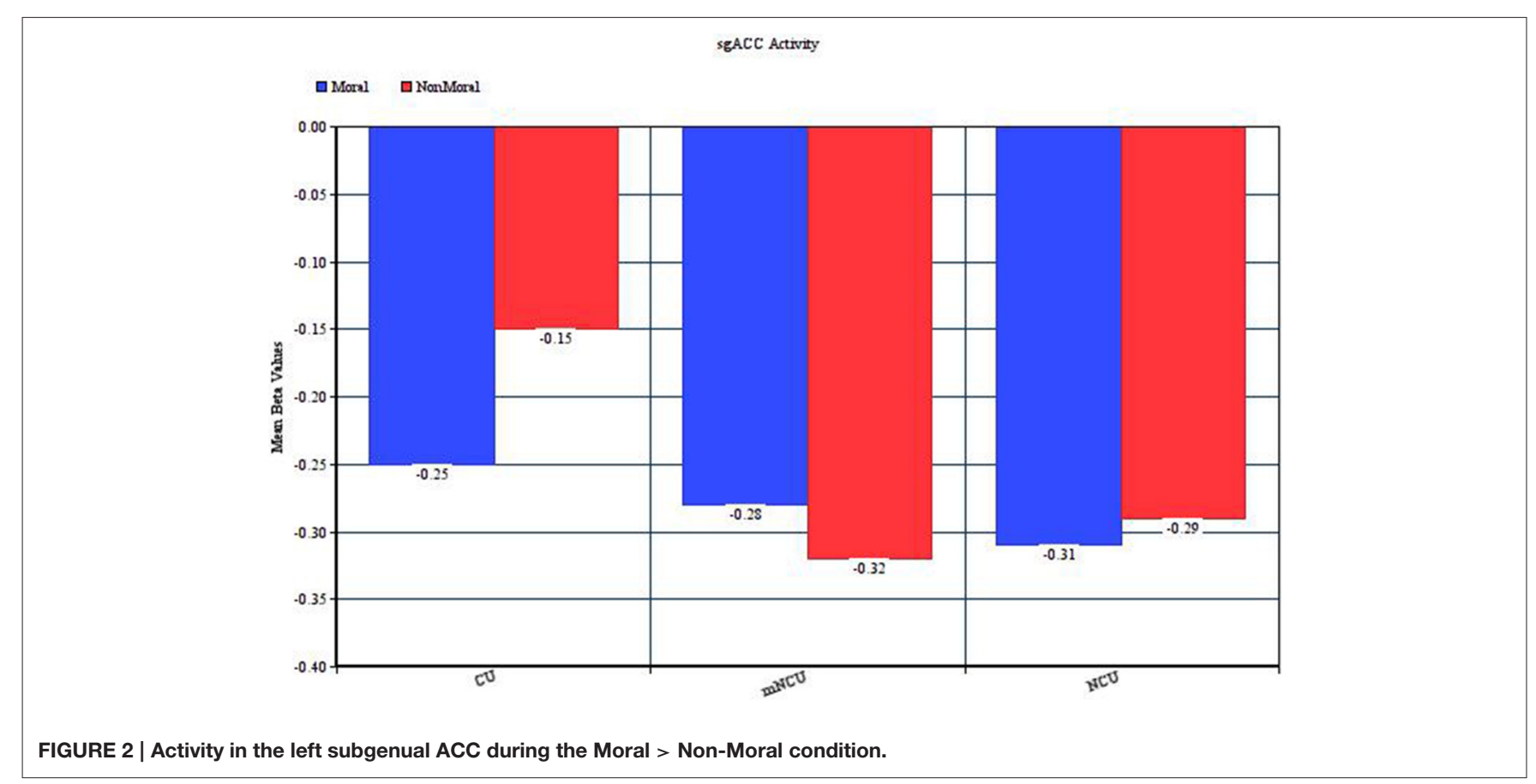


Factor 1 scores suggests that cocaine use has an independent and potentially additive impact on attentional allocation during implicit moral processing. Within the substance abuse literature, abnormal neural activity in the ACC amongst cocaine users has primarily been associated with the 'attentional bias' they exhibit toward cocaine-related stimuli (Goldstein et al., 2007, 2009, 2010; Ersche et al., 2010). An attentional bias toward cocaine related stimuli may have resulted in an attentional bias away from the morally relevant affective content of the stimuli. It is important to note, however, that support for this interpretation is limited by the fact that participants' allocation of attention during the implicit moral task was not directly measured. Future research into the interaction between substance abuse and psychopathy may benefit from testing this interpretation more rigorously. During implicit moral processing, this bias appears to have resulted in cocaine users being insensitive to the morally relevant affective content in the stimuli. Similarly, several different etiological models of psychopathy have proposed an attention deficit as being central to the disorder (Kiehl, 2006; Hiatt and Newman, 2006; MacCoon et al., 2004). The paralimbic dysfunction model hypothesizes that the deficit is in emotional attention specifically-whereby psychopaths are under-reactive to affective information outside the current focus of attention (Kiehl, 2006). This hypothesis has been supported by a number of studies showing that psychopaths tend to perform better than average when the task containing emotional information that is incongruent with performance (Christianson et al., 1996; Mitchell et al., 2006) and worse when it is relevant (Lorenz and Newman, 2002; Williamson et al., 1991). Moroever, this under-reactivity to affective information has been associated with hypoactivity in the rACC amongst psychopaths (Kiehl et al., 2001; Müller et al., 2003; Birbaumer et al., 2005).

In summary, former regular cocaine users exhibited abnormal neural activity during implicit moral cognition in several corticolimbic brain regions. Unlike their non-cocaine using peers, members of the Cocaine Users group failed to discriminate between morally irrelevant depictions of negative social scenarios and depictions of moral violations at a neural level. The frontostriatal regions in which this abnormal hypoactivity occurred suggest that this reflexive, perceptual discrimination is most likely rooted in affective processes. Thus, while the majority of the sample found the moral pictures to be more affectively arousing than the non-moral ones, those who had once regularly used cocaine did not.

These findings add to a growing body of research suggesting a deleterious effect of substance abuse on high-level socioaffective processes like moral cognition. Not only can drugs of abuse alter our natural reward pathway so that one does not find non-drug rewards to be arousing, but it can also lead to insensitivity toward negative stimuli- such as witnessing an immoral act. Consequently, abnormalities in this pathway, such as those seen in chronic cocaine abusers, may correspond to significant alterations in individuals' social cognitive processing. Within moral psychology, this is consistent with an increasingly popular view that striatal reward processing plays an important role in moral cognition - both in promoting prosociality and depressing immoral or antisocial behaviors. Within addiction research, alterations in socio-affective processing may help to explain both the antisocial behaviors of current and former addicts and the propensity of former addicts to relapse into substance use many years after withdrawal. Overvaluation of the individual's drug of choice may be coupled with a devaluation of prosocial reinforcers, such as spending time with friends or family, and a reduced aversion toward the negative outcomes associated with substance abuse.

\section{LIMITATIONS}

Several limitations of this study should be noted. First, the results of this study cannot be used to make any strong claims regarding the casual influence of cocaine use on moral intuition. It is possible that individuals prone to regular cocaine use exhibited the observed deficits in moral intuition before they began using cocaine.

Second, substance use severity ratings were based on selfreport, allowing for the possibility that some participants underreported their past or current substance use. However, there are several reasons to assume that actual under-reporting within our population was relatively low. Current substance use may have been under-reported due to a fear of negative consequences for reporting current drug use. However, all participants were assured that all of the information they revealed about themselves would remain confidential and that none of what they reported to the interviewer would have any impact on their institutional status. Additionally, past or current substance abuse may have been under-reported due to social desirability concerns. Existing research on the accuracy of self-reported cocaine use within incarcerated populations suggests that, while under-reporting does occur, incarcerated participants are less likely to underreport due to social desirability concerns than community samples (Harrison and Hughes, 1997; Hser, 1997; Fendrich et al., 1999). Within our own population, CUs and mNCUs did not significantly differ on impression management or self-deception, as measured by the BIDR. Moreover, within the CUs, social desirability was not correlated with self-reported cocaine use or self-reported abstinence from cocaine use.

The present study used a 1.5T Mobile MRI scanner. Whereas, we have published on the reliability of $1.5 \mathrm{~T}$ for fMRI (Kiehl et al., 2005), it is possible that additional effects may be found at higher field strengths. Nevertheless, we were able to confirm our hypotheses (and collect the data from this prison sample) with 1.5T MRI.

Finally, based on data for a separate study where urinary toxicology screens were administered during a research study at the same site, stimulant use during incarceration appears to be relatively uncommon and under-reporting of current stimulant use appears to be very low. Of 62 incarcerated participants taking part in a substance abuse treatment program, only 2 reported stimulant use during their incarceration. Additionally, out of 34 incarcerated participants who completed the ASI and received a UA, only 1 participant reported no current cocaine use, but tested positive for cocaine (Kiehl laboratory, unpublished data). 


\section{ACKNOWLEDGMENTS}

This research was supported by the following grants from the National Institute on Drug Abuse: 1R01DA026964-01A1, 1R01DA026505-01A1, 1R01DA020870-01 (PI: Kiehl).

\section{REFERENCES}

Adinoff, B. (2004). Neurobiologic processes in drug reward and addiction. Harv. Rev. Psychiatry 12, 305-320. doi: 10.1080/10673220490910844

Aguilar de Arcos, F., Verdejo-García, A., Peralta-Ramírez, M. I., Sánchez-Barrera, M., and Pérez-García, M. (2005). Experience of emotions in substance abusers exposed to images containing neutral, positive, and negative affective stimuli. Drug Alcohol Depend. 78, 159-167. doi: 10.1016/j.drugalcdep.2004.10.010

Amemori, K. I., and Graybiel, A. M. (2012). Localized microstimulation of primate pregenual cingulate cortex induces negative decision-making. Nat. Neurosci. 15, 776-785. doi: 10.1038/nn.3088

American Psychiatric Association. (1994). Diagnostic and Statistical Manual of Mental Disorders, Reprinted From: 4th Edn. Washington, DC.

Amodio, D. M., and Frith, C. D. (2006). Meeting of minds: the medial frontal cortex and social cognition. Nat. Rev. Neurosci. 7, 268-277. doi: $10.1038 / \mathrm{nrn} 1884$

Asensio, S., Romero, M. J., Palau, C., Sanchez, A., Senabre, I., Morales, J. L., et al. (2010). Altered neural response of the appetitive emotional system in cocaine addiction: an fMRI Study. Addict. Biol. 15, 504-516. doi: 10.1111/j.13691600.2010.00230.x

Basile, B., Mancini, F., Macaluso, E., Caltagirone, C., Frackowiak, R. S., and Bozzali, M. (2011). Deontological and altruistic guilt: evidence for distinct neurobiological substrates. Hum. Brain Mapp. 32, 229-239. doi: 10.1002/hbm.21009

Bechara, A., and Damasio, A. R. (2005). The somatic marker hypothesis: a neural theory of economic decision. Games Econ. Behav. 52, 336-372. doi: 10.1016/j.geb.2004.06.010

Birbaumer, N., Viet, R., Lotze, M., Erb, M., Hermann, C., Grodd, W., et al. (2005). Deficient fear conditioning in psychopathy - A functional magnetic resonance imaging study. Arch. Gen. Psychiatry 62, 799-805. doi: 10.1001/archpsyc.62.7.799

Bissière, S., Plachta, N., Hoyer, D., McAllister, K. H., Olpe, H. R., Grace, A. A., et al. (2008). The rostral anterior cingulate cortex modulates the efficiency of amygdala-dependent fear learning. Biol. Psychiatry 63, 821-831. doi: 10.1016/j.biopsych.2007.10.022

Bjork, J. M., Chen, G., and Hommer, D. W. (2012). Psychopathic tendencies and mesolimbic recruitment by cues for instrumental and passively obtained rewards. Biol. Psychol. 89, 408-415. doi: 10.1016/j.biopsycho.2011.12.003

Boccardi, M., Bocchetta, M., Aronen, H. J., Repo-Tiihonen, E., Vaurio, O., Thompson, P. M., et al. (2013). Atypical nucleus accumbens morphology in psychopathy: another limbic piece in the puzzle. Int. J. Law Psychiatry 36, 157-167. doi: 10.1016/j.ijlp.2013.01.008

Bowers, M. B., Malison, R. T., Seibyl, J. P., and Kosten, T. R. (1998). Plasma homovanillic acid and the dopamine transporter during cocaine withdrawal. Biol. Psychiatry 43, 278-281. doi: 10.1016/S0006-3223(97)00293-X

Brook, M., Brieman, C. L., and Kosson, D. S. (2013). Emotion processing in Psychopathy Checklist-assessed psychopathy: a review of the literature. Clin. Psychol. Rev. 33, 979-995. doi: 10.1016/j.cpr.2013.07.008

Brower, M. C., and Price, B. H. (2001). Neuropsychiatry of frontal lobe dysfunction in violent and criminal behaviour: a critical review. J. Neurol. Neurosurg. Psychiatry 71, 720-726. doi: 10.1136/jnnp.71.6.720

Buckholtz, J. W., Treadway, M. T., Cowan, R. L., Woodward, N. D., Benning, S. D., Li, R., et al. (2010). Mesolimbic dopamine reward system hypersensitivity in individuals with psychopathic traits. Nat. Neurosci. 13, 419-421. doi: 10.1038/nn.2510

Carmona-Perera, M., Verdejo-García, A., Young, L., Molina-Fernández, A., and Pérez-Garcia, M. (2012). Moral decision-making in polysubstance dependent individuals. Drug Alcohol Depend. 126, 389-392. doi: 10.1016/j.drugalcdep.2012.05.038

\section{SUPPLEMENTARY MATERIAL}

The Supplementary Material for this article can be found online at: http://journal.frontiersin.org/article/10.3389/fnhum. 2015.00565

Childress, A. R., Ehrman, R. N., Wang, Z., Li, Y., Sciortino, N., Hakun, J., et al. (2008). Prelude to Passion: limbic activation by "Unseen" drug and sexual cues. PLoS ONE 3:e1506. doi: 10.1371/journal.pone.0001506

Chiu, P. H., Holmes, A. J., and Pizzagalli, D. A. (2008). Dissociable recruitment of rostral anterior cingulate and inferior frontal cortex in emotional response inhibition. Neuroimage 42, 988-997. doi: 10.1016/j.neuroimage.2008.04.248

Christianson, S. Å., Forth, A. E., Hare, R. D., Strachan, C., Lidberg, L., and Thorell, L. H. (1996). Remembering details of emotional events: a comparison between psychopathic and nonpsychopathic offenders. Pers. Individ. Differences 20, 437-443. doi: 10.1016/0191-8869(95)00220-0

Ciaramelli, E., Muccioli, M., Làdavas, E., and di Pellegrino, G. (2007). Selective deficit in personal moral judgment following damage to ventromedial prefrontal cortex. Soc. Cogn. Affect. Neurosci. 2, 84-92 doi: 10.1093/scan/nsm001

Cleckley, H. (1976). The Mask of Sanity. St. Louis, MO: Mosby.

Critchley, H. D. (2005). Neural mechanisms of autonomic, affective, and cognitive integration. J. Comp. Neurol. 493, 154-166. doi: 10.1002/cne.20749

Cromheeke, S., and Mueller, S. C. (2014). Probing emotional influences on cognitive control: an ALE meta-analysis of cognition emotion interactions. Brain Struc. Funct. 219, 995-1008. doi: 10.1007/s00429-013-0549-Z

Cunha, P. J., Bechara, A., de Andrade, A. G., and Nicastri, S. (2011). Decision-making deficits linked to real-life social dysfunction in crack cocaine-dependent individuals. Am. J. Addict. 20, 78-86. doi: 10.1111/j.15210391.2010.00097.x

Decety, J., and Cacioppo, S. (2012). The speed of morality: a highdensity electrical neuroimaging study. J. Neurophysiol. 108, 3068-3072. doi: 10.1152/jn.00473.2012

Decety, J., Chen, C., Harenski, C., and Kiehl, K. A. (2013). An fMRI study of affective perspective taking in individuals with psychopathy: imagining another in pain does not evoke empathy. Front. Hum. Neurosci. 7:489. doi: 10.3389/fnhum.2013.00489

Decety, J., and Jackson, P. L. (2004). The functional architecture of human empathy. Behav. Cogn. Neurosci. Rev. 3, 71-100. doi: $10.1177 / 1534582304267187$

Decety, J., Michalska, K. J., and Kinzler, K. D. (2012). The contribution of emotion and cognition to moral sensitivity: a neurodevelopmental study. Cereb. Cortex 22, 209-220. doi: 10.1093/cercor/bhr111

Diekhof, E. K., Geier, K., Falkai, P., and Gruber, O. (2011). Fear is only as deep as the mind allows: a coordinate-based meta-analysis of neuroimaging studies on the regulation of negative affect. Neuroimage 58, 275-285. doi: 10.1016/j.neuroimage.2011.05.073

Drevets, W. C., Savitz, J., and Trimble, M. (2008). The subgenual anterior cingulate cortex in mood disorders. CNS Spectr. 13, 663.

Dunning, J. P., Parvaz, M. A., Hajcak, G., Maloney, T., Alia-Klein, N., Woicik, P. A., et al. (2011). Motivated attention to cocaine and emotional cues in abstinent and current cocaine users - an ERP study. Eur. J. Neurosci. 33, 1716-1723. doi: 10.1111/j.1460-9568.2011.07663.x

Eaton, N. R., Rodriguez-Seijas, C., Carragher, N., and Krueger, R. F. (2015). Transdiagnostic factors of psychopathology and substance use disorders: a review. Soc. Psychiatry Psychiatr. Epidemiol. 50, 171-182. doi: 10.1007/s00127014-1001-2

Egner, T., Etkin, A., Gale, S., and Hirsch, J. (2008). Dissociable neural systems resolve conflict from emotional versus nonemotional distracters. Cereb. Cortex 18, 1475-1484. doi: 10.1093/cercor/bhm179

Ermer, E., Cope, L. M., Nyalakanti, P. K., Calhoun, V. D., and Kiehl, K. A. (2012). Aberrant paralimbic gray matter in criminal psychopathy. J. Abnorm. Psychol. 121, 649. doi: 10.1037/a0026371

Ersche, K. D., Bullmore, E. T., Craig, K. J., Shabbir, S. S., Abbott, S., Müller, U., et al. (2010). Influence of compulsivity of drug abuse on dopaminergic modulation 
of attentional bias in stimulant dependence. Arch. Gen. Psychiatry 67, 632-644. doi: 10.1001/archgenpsychiatry.2010.60

Etkin, A., Egner, T., and Kalisch, R. (2011). Emotional processing in anterior cingulate and medial prefrontal cortex. Trends Cogn. Sci. 15, 85-93. doi: 10.1016/j.tics.2010.11.004

Etkin, A., Egner, T., Peraza, D. M., Kandel, E. R., and Hirsch, J. (2006). Resolving emotional conflict: a role for the rostral anterior cingulate cortex in modulating activity in the amygdala. Neuron 51, 871-882. doi: 10.1016/j.neuron.2006.07.029

Fendrich, M., Johnson, T. P., Sudman, S., Wislar, J. S., and Spiehler, V. (1999). Validity of drug use reporting in a high-risk community sample: a comparison of cocaine and heroin survey reports with hair tests. Am. J. Epidemiol. 149, 955-962. doi: 10.1093/oxfordjournals.aje.a009740

Fernández-Serrano, M. J., Lozano, O., Pérez-García, M., and VerdejoGarcía, A. (2010). Impact of severity of drug use on discrete emotions recognition in polysubstance abusers. Drug Alcohol Depend. 109, 57-64. doi: 10.1016/j.drugalcdep.2009.12.007

Ferrari, V., Smeraldi, E., Bottero, G., and Politi, E. (2014). Addiction and empathy: a preliminary analysis. Neurol. Sci. 35, 855-859. doi: 10.1007/s10072-01 3-1611-6

First, M. B., Spitzer, R. L., Gibbon, M., and Williams, J. B. W. (2002). Structured Clinical Interview for DSM-IV-TR Axis I Disorders, Research Version, Nonpatient Edition (SCID-I/NP). New York, NY: Biometrics Research; New York State Psychiatric Institute.

Foisy, M. L., Philippot, P., Verbanck, P., Pelc, I., Van der Straten, G., and Kornreich, C. (2005). Emotional facial expression decoding impairment in persons dependent on multiple substances: impact of a history of alcohol dependence. J. Stud. Alcohol. 66, 673-681. doi: 10.15288/jsa.2005. 66.673

Fox, H. C., Axelrod, S. R., Paliwal, P., Sleeper, J., and Sinha, R. (2007). Difficulties in emotion regulation and impulse control during cocaine abstinence. Drug Alcohol Depend. 89, 298-301. doi: 10.1016/j.drugalcdep. 2006.12.026

Fox, H. C., Bergquist, K. L., Casey, J., Hong, K. A., and Sinha, R. (2011). Selective cocaine-related difficulties in emotional intelligence: relationship to stress and impulse control. Am. J. Addict. 20, 151-160. doi: 10.1111/j.15210391.2010.00108.x

Fulero, S. (1996). "Review of the hare psychopathy checklist-revised," in 12th Mental Measurements Yearbook, eds J. C. Conoley and J. C. Impara (Lincoln, NE: Buros Institute), 453-454.

Fumagalli, M., and Priori, A. (2012). Functional and clinical neuroanatomy of morality. Brain 135, 2006-2021. doi: 10.1093/brain/awr334

Glenn, A. L., Raine, A., Yaralian, P. S., and Yang, Y. (2010). Increased volume of the striatum in psychopathic individuals. Biol. Psychiatry 67, 52-58. doi: 10.1016/j.biopsych.2009.06.018

Goldstein, R. Z., Alia-Klein, N., Tomasi, D., Carrillo, J. H., Maloney, T., Woicik, P. A., et al. (2009). Anterior cingulate cortex hypoactivations to an emotionally salient task in cocaine addiction. Proc. Natl. Acad. Sci. U.S.A. 106, 9453-9458. doi: 10.1073/pnas.0900491106

Goldstein, R. Z., Tomasi, D., Rajaram, S., Cottone, L. A., Zhang, L., Maloney, T., et al. (2007). Role of the anterior cingulate and medial orbitofrontal cortex in processing drug cues in cocaine addiction. Neuroscience 144, 1153-1159. doi: 10.1016/j.neuroscience.2006.11.024

Goldstein, R. Z., Woicik, P. A., Maloney, T., Tomasi, D., Alia-Klein, N., Shan, J., et al. (2010). Oral methylphenidate normalizes cingulate activity in cocaine addiction during a salient cognitive task. Proc. Natl. Acad. Sci. U.S.A. 107, 16667-16672. doi: 10.1073/pnas.1011455107

Grafman, J., Schwab, K., Warden, D., Pridgen, A., Brown, H. R., and Salazar, A. M. (1996). Frontal lobe injuries, violence, and aggression a report of the vietnam head injury study. Neurology 46, 1231-1231. doi: 10.1212/WNL. 46.5.1231

Green, S., Ralph, M. A. L., Moll, J., Stamatakis, E. A., Grafman, J., and Zahn, R. (2010). Selective functional integration between anterior temporal and distinct fronto-mesolimbic regions during guilt and indignation. Neuroimage 52, 1720-1726. doi: 10.1016/j.neuroimage.2010.05.038

Greene, J. D., Nystrom, L. E., Engell, A. D., Darley, J. M., and Cohen, J. D. (2004). The neural bases of cognitive conflict and control in moral judgment. Neuron 44, 389-400. doi: 10.1016/j.neuron.2004.09.027
Greene, J. D., Sommerville, R. B., Nystrom, L. E., Darley, J. M., and Cohen, J. D. (2001). An fMRI investigation of emotional engagement in moral judgment. Science 293, 2105-2108. doi: 10.1126/science.1062872

Greicius, M. D., Flores, B. H., Menon, V., Glover, G. H., Solvason, H. B., Kenna, H., et al. (2007). Resting-state functional connectivity in major depression: abnormally increased contributions from subgenual cingulate cortex and thalamus. Biol. Psychiatry 62, 429-437. doi: 10.1016/j.biopsych.2006.09.020

Haas, B. W., Omura, K., Amin, Z., Constable, R. T., and Canli, T. (2006). Functional connectivity with the anterior cingulate is associated with extraversion during the emotional Stroop task. Soc. Neurosci. 1, 16-24. doi: $10.1080 / 17470910600650753$

Haber, S. N. (2011). "Neuroanatomy of reward: a view from the ventral striatum," in Neurobiology of Sensation and Reward, ed J. A. Gottfried (Boca Raton, FL: CRC Press), 235-262.

Haidt, J. (2001). The emotional dog and its rational tail: a social intuitionist approach to moral judgment. Psychol. Rev. 108, 814-834. doi: 10.1037/0033295X.108.4.814

Hare, R. D., and Neumann, C. S. (2008). Psychopathy as a clinical and empirical construct. Annu. Rev. Clin. Psychol. 4, 217-246. doi: 10.1146/annurev.clinpsy.3.022806.091452

Hare, R. D. (1980). A research scale for the assessment of psychopathy in criminal populations. Pers. Individ. Diff. 1, 111-119. doi: 10.1016/0191-8869(80)90028-8

Hare, R. D. (1996). Psychopathy a clinical construct whose time has come. Crim. Justice Behav. 23, 25-54. doi: 10.1177/0093854896023001004

Hare, R. D. (2003). The Hare Psychopathy Checklist - Revised. Toronto, ON: Multi-Health Systems.

Harenski, C. L., Antonenko, O., Shane, M. S., and Kiehl, K. A. (2010a). A functional imaging investigation of moral deliberation and moral intuition. Neuroimage 49, 2707-2716. doi: 10.1016/j.neuroimage.2009.10.062

Harenski, C. L., and Hamann, S. (2006). Neural correlates of regulating negative emotions related to moral violations. Neuroimage 30, 313-324. doi: 10.1016/j.neuroimage.2005.09.034

Harenski, C. L., Harenski, K. A., Shane, M. S., and Kiehl, K. A. (2010b). Aberrant neural processing of moral violations in criminal psychopaths. J. Abnorm. Psychol. 119, 863-874. doi: 10.1037/A0020979

Harenski, C. L., Kim, S. H., and Hamann, S. (2009). Neuroticism and psychopathy predict brain activation during moral and nonmoral emotion regulation. Cogn. Affect. Behav. Neurosci. 9, 1-15. doi: 10.3758/CABN.9.1.1

Harris, G. T., Rice, M. E., and Cormier, C. A. (1991). Psychopathy and violent recidivism. Law Hum. Behav. 15, 625-637. doi: 10.1007/BF01065856

Harrison, L., and Hughes, A. (1997). The Validity of self-reported DRUG use: Improving the Accuracy of Survey Estimates. Rockville, MD: National Institute on Drug Abuse (NIH Publication No. 97-4147, NIDA Research Monograph 167).

Hart, S. D., and Hare, R. D. (1989). Discriminant validity of the Psychopathy Checklist in a forensic psychiatric population. Psychol. Assess. J. Consult. Clin. Psychol. 1, 211-218. doi: 10.1037/1040-3590.1.3.211

Haslam, N., Holland, E., and Kuppens, P. (2012). Categories versus dimensions in personality and psychopathology: a quantitative review of taxometric research. Psychol. Med. 42, 903-920. doi: 10.1017/S0033291711001966

Hauser, M. D. (2006). The liver and the moral organ. Soc. Cogn. Affect. Neurosci. 1, 214-220. doi: 10.1093/scan/nsl026

Heekeren, H. R., Wartenburger, I., Schmidt, H., Schwintowski, H. P., and Villringer, A. (2003). An fMRI study of simple ethical decision-making. Neuroreport 14, 1215-1219. doi: 10.1097/00001756-200307010-00005

Hemphill, J. F., Templeman, R., Wong, S., and Hare, R. D. (1998). Psychopathy and crime: recidivism and criminal careers. Psychopathy 88, 375-399. doi: 10.1007/978-94-011-3965-6_16

Hiatt, K. D., and Newman, J. P. (2006). "Understanding psychopathy: the cognitive side," in Handbook of Psychopathy, ed C. J. Patrick (New York, NY: Guilford Press), 334-352.

Holroyd, K. B., Adrover, M. F., Fuino, R. L., Bock, R., Kaplan, A. R., Gremel, C. M., et al. (2014). Loss of feedback inhibition via D2 autoreceptors enhances acquisition of cocaine taking and reactivity to drug-paired cues. Neuropsychopharmacology 40, 1495-1509. doi: 10.1038/npp.2014.336

Hoppenbrouwers, S. S., Nazeri, A., de Jesus, D. R., Stirpe, T., Felsky, D., Schutter, D. J., et al. (2013). White matter deficits in psychopathic offenders and correlation with factor structure. PLoS ONE 8:e72375. doi: 10.1371/journal.pone.0072375 
Horvitz, J. C. (2000). Mesolimbocortical and nigrostriatal dopamine responses to salient non-reward events. Neuroscience 96, 651-656. doi: 10.1016/S03064522(00)00019-1

Hser, Y. I. (1997). Self-reported drug use: results of selected empirical investigations of validity. NIDA Res. Monogr. 167, 320-343.

Hulka, L. M., Eisenegger, C., Preller, K. H., Vonmoos, M., Jenni, D., Bendrick, K., et al. (2014). Altered social and non-social decision-making in recreational and dependent cocaine users. Psychol. Med. 44, 1015-1028. doi: $10.1017 /$ S0033291713001839

Iordan, A. D., Dolcos, S., and Dolcos, F. (2013). Neural signatures of the response to emotional distraction: a review of evidence from brain imaging investigations. Front. Hum. Neurosci. 7:200. doi: 10.3389/fnhum. 2013.00200

Izuma, K., Saito, D. N., and Sadato, N. (2010). Processing of the incentive for social approval in the ventral striatum during charitable donation. J. Cogn. Neurosci. 22, 621-631. doi: 10.1162/jocn.2009.21228

Johansen-Berg, H., Gutman, D. A., Behrens, T. E., Matthews, P. M., Rush-worth, M. F., Katz, E., et al. (2007). Anatomical connectivity of the subgenual cingulate region targeted with deep brain stimulation for treatment-resistant depression. Cereb. Cortex 18, 1374-1383. doi: 10.1093/cercor/bhm167

Kanske, P., and Kotz, S. A. (2011a). Emotion speeds up conflict resolution: a new role for the ventral anterior cingulate cortex? Cereb. Cortex 21, 911-919. doi: 10.1093/cercor/bhq157

Kanske, P., and Kotz, S. A. (2011b). Emotion triggers executive attention: anterior cingulate cortex and amygdala responses to emotional words in a conflict task. Hum. Brain Mapp. 32, 198-208. doi: 10.1002/hbm. 21012

Kemmis, L., Hall, J. K., Kingston, R., and Morgan, M. J. (2007). Impaired fear recognition in regular recreational cocaine users. Psychopharmacology 194, 151-159. doi: 10.1007/s00213-007-0829-5

Kiehl, K. A., Smith, A. M., Hare, R. D., Mendrek, A., Forster, B. B., Brink, J., et al. (2001). Limbic abnormalities in affective processing by criminal psychopaths as revealed by functional magnetic resonance imaging. Biol. Psychiatry 50, 677-684. doi: 10.1016/S0006-3223(01)01222-7

Kiehl, K. A., Stevens, M. C., Laurens, K. R., Pearlson, G., Calhoun, V. D., and Liddle, P. F. (2005). An adaptive reflexive processing model of neurocognitive function: supporting evidence from a large scale $(n=100)$ fMRI study of an auditory oddball task. Neuroimage 25, 899-915. doi: 10.1016/j.neuroimage.2004.12.035

Kiehl, K. A. (2006). A cognitive neuroscience perspective on psychopathy: evidence for paralimbic system dysfunction. Psychiatry Res. 142, 107-128. doi: 10.1016/j.psychres.2005.09.013

Kim, Y. T., Song, H. J., Seo, J. H., Lee, J. J., Lee, J., Kwon, D. H., et al. (2011). The differences in neural network activity between methamphetamine abusers and healthy subjects performing an emotion-matching task: functional MRI study. NMR Biomed. 24, 1392-1400. doi: 10.1002/nbm.1702

Koenigs, M., and Tranel, D. (2007). Irrational economic decision-making after ventromedial prefrontal damage: evidence from the ultimatum game. J. Neurosci. 27, 951-956.

Koenigs, M., Young, L., Adolphs, R., Tranel, D., Cushman, F., Hauser, M., et al. (2007). Damage to the prefrontal cortex increases utilitarian moral judgements. Nature 446, 908-911. doi: 10.1038/nature05631

Kornreich, C., Brevers, D., Ermer, E., Hanak, C., Verbanck, P., Campanella, S., et al. (2013). Polysubstance dependent patients display a more utilitarian profile in moral decision-making than alcohol-dependent patients, depressive patients and controls. Drug Alcohol Depend. 132, 434-440. doi: 10.1016/j.drugalcdep.2013.03.005

Kosson, D. S., Budhani, S., Nakic, M., Chen, G., Saad, Z. S., Vythilingam, M., et al. (2006). The role of the amygdala and rostral anterior cingulate in encoding expected outcomes during learning. Neuroimage 29, 1161-1172. doi: 10.1016/j.neuroimage.2005.07.060

Lamm, C., Decety, J., and Singer, T. (2011). Meta-analytic evidence for common and distinct neural networks associated with directly experienced pain and empathy for pain. Neuroimage 54, 2492-2502. doi: 10.1016/j.neuroimage.2010.10.014

Lang, P. J., Bradley, M. M., and Cuthbert, B. N. (1995). International Affective Picture System (IAPS). Bethesda, MD: National Institute of Mental Health Center for the Study of Emotion and Attention.
Lin, A., Adolphs, R., and Rangel, A. (2012). Social and monetary reward learning engage overlapping neural substrates. Soc. Cogn. Affect. Neurosci. 7, 274-281. doi: $10.1093 /$ scan/nsr006

Lindquist, K. A., Wager, T. D., Kober, H., Bliss-Moreau, E., and Barrett, L. F. (2012). The brain basis of emotion: a meta-analytic review. Behav. Brain Sci. 35, 121-143. doi: 10.1017/S0140525X11000446

Lorenz, A. R., and Newman, J. P. (2002). Deficient response modulation and emotion processing in low-anxious caucasian psychopathic offenders: results from a lexical decision task. Emotion 2, 91-104. doi: 10.1037/1528-3542. 2.2.91

Luo, Q., Nakic, M., Wheatley, T., Richell, R., Martin, A., and Blair, R. J. R. (2006). The neural basis of implicit moral attitude-an IAT study using event-related fMRI. Neuroimage 30, 1449-1457. doi: 10.1016/j.neuroimage.2005.11.005

MacCoon, D. G., Wallace, J. F., and Newman, J. P. (2004). "Self-regulation: the context-appropriate allocation of attentional capacity to dominant and non-dominant cues," in Handbook of Self-Regulation: Research Theory, and Applications, eds R. F. Baumeister and K. D. Vohs (New York, NY: Guilford), 422-446.

Mazaika, P. K., Hoeft, F., Glover, G. H., and Reiss, A. L. (2009). Methods and software for fMRI analysis of clinical subjects. Neuroimage 47:S58. doi: 10.1016/S1053-8119(09)70238-1

Mclellan, A. T., Kushner, H., Metzger, D., Peters, R., Smith, I., Grissom, G., et al. (1992). The 5th Edition of the Addiction Severity Index. J. Subst. Abuse Treat. 9, 199-213. doi: 10.1016/0740-5472(92)90062-S

Mitchell, D. G., Richell, R. A., Leonard, A., Blair, R. J. (2006). Emotion at the expense of cognition: psychopathic individuals outperform controls on an operant response task. J. Abnorm. Psychol. 115, 559-566. doi: 10.1037/0021843X.115.3.559

Mohanty, A., Engels, A. S., Herrington, J. D., Heller, W., Ho, M. H., Banich, M. T., et al. (2007). Differential engagement of anterior cingulate cortex subdivisions for cognitive and emotional function. Psychophysiology 44, 343-351. doi: 10.1111/j.1469-8986.2007.00515.x

Moll, J., de Oliveira-Souza, R., Bramati, I. E., and Grafman, J. (2002a). Functional networks in emotional moral and nonmoral social judgments. Neuroimage 16, 696-703. doi: 10.1006/nimg.2002.1118

Moll, J., de Oliveira-Souza, R., Eslinger, P. J., Bramati, I. E., Mourão-Miranda, J., Andreiuolo, P. A., et al. (2002b). The neural correlates of moral sensitivity: a functional magnetic resonance imaging investigation of basic and moral emotions. J. Neurosci. 22, 2730-2736.

Moll, J., de Oliveira-Souza, R., Garrido, G. J., Bramati, I. E., Caparelli-Daquer, E. M. A., Paiva, M. L. M. F., et al. (2007). The self as a moral agent: link-ling the neural bases of social agency and moral sensitivity. Soc. Neurosci. 2, 336-352. doi: 10.1080/17470910701392024

Moll, J., Eslinger, P. J., and Oliveira-Souza, R. (2001). Frontopolar and anterior temporal cortex activation in a moral judgment task: preliminary functional MRI results in normal subjects. Arq. Neuropsiquiatr. 59, 657-664. doi: 10.1590/S0004-282X2001000500001

Moll, J., Krueger, F., Zahn, R., Pardini, M., de Oliveira-Souza, R., and Grafman, J. (2006). Human fronto-mesolimbic networks guide decisions about charitable donation. Proc. Natl. Acad. Sci. U.S.A. 103, 15623-15628. doi: 10.1073/pnas.0604475103

Moretto, G., Làdavas, E., Mattioli, F., and di Pellegrino, G. (2010). A psychophysiological investigation of moral judgment after ventromedial prefrontal damage. J. Cogn. Neurosci. 22, 1888-1899. doi: 10.1162/jocn.2009.21367

Morgan, M. J., and Marshall, J. P. (2013). Deficient fear recognition in regular cocaine users is not attributable to elevated impulsivity or conduct disorder prior to cocaine use. J. Psychopharmacol. 27, 526-532. doi: $10.1177 / 0269881113477708$

Müller, J. L., Sommer, M., Wagner, V., Lange, K., Taschler, H., Röder, C. H., et al. (2003). Abnormalities in emotion processing within cortical and subcortical regions in criminal psychopaths: evidence from a functional magnetic resonance imaging study using pictures with emotional content. Biol. Psychiatry 54, 152-162. doi: 10.1016/S0006-3223(02)01749-3

Muthén, B. (2006). Should substance use disorders be considered as categorical or dimensional? Addiction 101, 6-16. doi: 10.1111/j.1360-0443.2006.01583.x

Nakic, M., Smith, B. W., Busis, S., Vythilingam, M., and Blair, R. J. (2006). The impact of affect and frequency on lexical decision: the role of the 
amygdala and inferior frontal cortex. Neuroimage 31, 1752-1761. doi: 10.1016/j.neuroimage.2006.02.022

Ochsner, K. N., Hughes, B., Robertson, E. R., Cooper, J. C., and Gabrieli, J. D. (2009). Neural systems supporting the control of affective and cognitive conflicts. J. Cogn. Neurosci. 21, 1841-1854. doi: 10.1162/jocn.2009. 21129

Ochsner, K. N., Ray, R. D., Cooper, J. C., Robertson, E. R., Chopra, S., Gabrieli, J. D., et al. (2004). For better or for worse: neural systems supporting the cognitive down-and up-regulation of negative emotion. Neuroimage 23, 483-499. doi: 10.1016/j.neuroimage.2004.06.030

Paulhus, D. L. (1984). Two-component models of socially desirable responding. J. Pers. Soc. Psychol. 46, 598-609. doi: 10.1037/0022-3514.46.3.598

Phillips, M. L., Drevets, W. C., Rauch, S. L., and Lane, R. (2003). Neurobiology of emotion perception I: the neural basis of normal emotion perception. Biol. Psychiatry 54, 504-514. doi: 10.1016/S0006-3223(03)00168-9

Pissiota, A., Frans, O., Michelgård, A., Appel, L., Långström, B., Flaten, M. A., et al. (2003). Amygdala and anterior cingulate cortex activation during affective startle modulation: a PET study of fear. Eur. J. Neurosci. 18, 1325-1331. doi: 10.1046/j.1460-9568.2003.02855.x

Pizarro, D. A., and Bloom, P. (2003). The intelligence of the moral intuitions: comment on Haidt (2001). Psychol. Rev. 110, 193-196. doi: 10.1037/0033295X.110.1.193

Prehn, K., Wartenburger, I., Mériau, K., Scheibe, C., Goodenough, O. R., Villringer, A., et al. (2007). Individual differences in moral judgment competence influence neural correlates of socio-normative judgments. Soc. Cogn. Affect. Neurosci. 3, 33-46. doi: 10.1093/scan/nsm037

Preller, K. H., Hulka, L. M., Vonmoos, M., Jenni, D., Baumgartner, M. R., Seifritz, E., et al. (2014). Impaired emotional empathy and related social network deficits in cocaine users. Addict. Biol. 19, 452-466. doi: 10.1111/adb.12070

Pruessner, J. C., Champagne, F., Meaney, M. J., and Dagher, A. (2004). Dopamine release in response to a psychological stress in humans and its relationship to early life maternal care: a positron emission tomography study using [11C] raclopride. J. Neurosci. 24, 2825-2831. doi: 10.1523/JNEUROSCI.3422-03.2004

Pujara, M., Motzkin, J. C., Newman, J. P., Kiehl, K. A., and Koenigs, M. (2013). Neural correlates of reward and loss sensitivity in psychopathy. Soc. Cogn. Affect. Neurosci. 9, 794-801. doi: 10.1093/scan/nst054

Raz, G., Jacob, Y., Gonen, T., Winetraub, Y., Flash, T., Soreq, E., et al. (2014). Cry for her or cry with her: context-dependent dissociation of two modes of cinematic empathy reflected in network cohesion dynamics. Soc. Cogn. Affect. Neurosci. 9, 30-38. doi: 10.1093/scan/nst052

Ritz, M. C., Lamb, R. J., and Kuhar, M. J. (1987). Cocaine receptors on dopamine transporters are related to self-administration of cocaine. Science 237, 1219-1223. doi: 10.1126/science.2820058

Rolls, E. T., Hornak, J., Wade, D., and McGrath, J. (1994). Emotion-related learning in patients with social and emotional changes associated with frontal lobe damage. J. Neurol. Neurosurg. Psychiatry 57, 1518-1524. doi: 10.1136/jnnp.57.12.1518

Rolls, E. T. (2004). The functions of the orbitofrontal cortex. Brain Cogn. 55, 11-29. doi: 10.1016/S0278-2626(03)00277-X

Ryan, J. J., Lopez, S. J., and Werth, T. R. (1999). Development and preliminary validation of a Satz-Mogel short form of the WAIS-III in a sample of persons with substance abuse disorders. Int. J. Neuroscience. 98, 131-140. doi: $10.3109 / 00207459908994796$

Schiach-Borg, J., Hynes, C., Van Horn, J., Grafton, S., and Sinnott-Armstrong, W. (2006). Consequences, action, and intention as factors in moral judgments: an fMRI investigation. J. Cogn. Neurosci. 18, 803-817. doi: 10.1162/jocn.2006.18.5.803

Schiach-Borg, J., Lieberman, D., and Kiehl, K. A. (2008). Infection, incest, and iniquity: investigating the neural correlates of disgust and morality. J. Cogn. Neurosci. 20, 1529-1546. doi: 10.1162/jocn.2008.20109

Schiffer, B., Müller, B. W., Scherbaum, N., Hodgins, S., Forsting, M., Wiltfang, J., et al. (2011). Disentangling structural brain alterations associated with violent behavior from those associated with substance use disorders.Archiv. Gen. Psychiatry 68, 1039-1049. doi: 10.1001/archgenpsychiatry.2011.61

Shenhav, A., and Greene, J. D. (2010). Moral judgments recruit domaingeneral valuation mechanisms to integrate representations of probability and magnitude. Neuron 67, 667-677. doi: 10.1016/j.neuron.2010.07.020
Skuse, D. H., and Gallagher, L. (2009). Dopaminergic-neuropeptide interactions in the social brain. Trends Cogn. Sci. 13, 27-35. doi: 10.1016/j.tics.2008.09.007

Smith, S. S., and Newman, J. P. (1990). Alcohol and drug-abuse dependence disorders in psychopathic and nonpsychopathic criminal offenders. J. Abnorm. Psychol. 99, 430-439. doi: 10.1037/0021-843X.99.4.430

Sommer, M., Rothmayr, C., Döhnel, K., Meinhardt, J., Schwerdtner, J., Sodian, B., et al. (2010). How should I decide? The neural correlates of everyday moral reasoning. Neuropsychologia 48, 2018-2026. doi: 10.1016/j.neuropsychologia.2010.03.023

Thomas, B. C., Croft, K. E., and Tranel, D. (2011). Harming kin to save strangers: further evidence for abnormally utilitarian moral judgments after ventromedial prefrontal damage. J. Cogn. Neurosci. 23, 2186-2196. doi: 10.1162/jocn.2010.21591

Todd, R. M., Taylor, M. J., Robertson, A., Cassel, D. B., Doesberg, S. M., Lee, D. H., et al. (2014). Temporal-spatial neural activation patterns linked to perceptual encoding of emotional salience. PLOS ONE 9:e93753. doi: 10.1371/journal.pone.0093753

Verdejo-García, A., and Bechara, A. (2009). A somatic marker theory of addiction. Neuropharmacology 56, 48-62. doi: 10.1016/j.neuropharm.2008.07.035

Verdejo-García, A., Contreras-Rodríguez, O., Fonseca, F., Cuenca, A., SorianoMas, C., Rodriguez, J., et al. (2012). Functional alteration in frontolimbic systems relevant to moral judgment in cocaine-dependent subjects. Addict. Biol. 19, 272-281. doi: 10.1111/j.1369-1600.2012.00472.x

Verdejo-García, A., Rivas-Pérez, C., Vilar-López, R., and Pérez-García, M. (2007). Strategic self-regulation, decision-making and emotion processing in polysubstance abusers in their first year of abstinence. Drug Alcohol Depend. 86, 139-146. doi: 10.1016/j.drugalcdep.2006.05.024

Vogt, B. A., and Vogt, L. J. (2009). "Opioids, placebos and descending control of pain and stress systems," in Cingulate Neurobiology and Disease, ed B. A. Vogt (Oxford: Oxford University Press), 339e364.

Vogt, B. A. (2005). Pain and emotion interactions in subregions of the cingulate gyrus. Nat. Rev. Neurosci. 6, 533-544. doi: 10.1038/nrn1704

Volkow, N. D., Baler, R. D., and Goldstein, R. Z. (2011). Addiction: pulling at the neural threads of social behaviors. Neuron 69, 599-602. doi: 10.1016/j.neuron.2011.01.027

Volkow, N. D., Fowler, J. S., Wang, G. J., Telang, F., Logan, J., Jayne, M., et al. (2010). Cognitive control of drug craving inhibits brain reward regions in cocaine abusers. Neuroimage 49, 2536-2543. doi: 10.1016/j.neuroimage.2009.10.088

Volkow, N. D., Fowler, J. S., Wolf, A. P., Schlyer, D., Shiue, C. Y., Alpert, R., et al. (1990). Effects of chronic cocaine abuse on postsynaptic dopamine receptors. Am. J. Psychiatry 147, 719-724. doi: 10.1176/ajp.147.6.719

Volkow, N. D., Wang, G. J., Telang, F., Fowler, J. S., Logan, J., Childress, A. R., et al. (2006). Cocaine cues and dopamine in dorsal striatum: mechanism of craving in cocaine addiction. J. Neurosci. 26, 6583-6588. doi: 10.1523/JNEUROSCI.154406.2006

Wagner, U., N’Diaye, K., Ethofer, T., and Vuilleumier, P. (2011). Guilt-specific processing in the prefrontal cortex. Cereb. Cortex 21, 2461-2470. doi: $10.1093 /$ cercor/bhr016

Walsh, Z., Allen, L. C., and Kosson, D. S. (2007). Beyond social deviance: substance use disorders and the dimensions of psychopathy. J. Pers. Disord. 21, 273-288. doi: $10.1521 /$ pedi.2007.21.3.273

Wechsler, D. (1997). Wechsler Adult Intelligence Scale. New York, NY: Psychological Corporation.

Whalen, P. J., Bush, G., McNally, R. J., Wilhelm, S., McInerney, S. C., Jenike, M. A., et al. (1998). The emotional counting Stroop paradigm: a functional magnetic resonance imaging probe of the anterior cingulate affective division. Biol. Psychiatry 44, 1219-1228. doi: 10.1016/S0006-3223(98)00251-0

Wiech, K., Kahane, G., Shackel, N., Farias, M., Savulescu, J., and Tracey, I. (2013). Cold or calculating? Reduced activity in the subgenual cingulate cortex reflects decreased emotional aversion to harming in counterintuitive utilitarian judgment. Cognition 126, 364-372. doi: 10.1016/j.cognition.2012. 11.002

Williamson, S., Harpur, T. J., and Hare, R. D. (1991). Abnormal processing of affective words by psychopaths. Psychophysiology 28, 260-273.

Young, L., and Dungan, J. (2012). Where in the brain is morality? Everywhere and maybe nowhere. Soc. Neurosci. 7, 1-10. doi: 10.1080/17470919.2011.569146 
Young, L., and Saxe, R. (2009). An FMRI investigation of spontaneous mental state inference for moral judgment. J. Cogn. Neurosci. 21, 1396-1405. doi: 10.1162/jocn.2009.21137

Zahn, R., de Oliveira-Souza, R., Bramati, I., Garrido, G., and Moll, J. (2009b). Subgenual cingulate activity reflects individual differences in empathic concern. Neurosci. Lett. 457, 107-110. doi: 10.1016/j.neulet.2009.03.090

Zahn, R., Moll, J., Paiva, M., Garrido, G., Krueger, F., Huey, E. D., et al. (2009a). The neural basis of human social values: evidence from functional MRI. Cereb. Cortex 19, 276-283. doi: 10.1093/cercor/bhn080

Zaki, J., and Ochsner, K. N. (2012). The neuroscience of empathy: progress, pitfalls and promise. Nat. Neurosci. 15, 675-680. doi: 10.1038/nn.3085
Conflict of Interest Statement: The authors declare that the research was conducted in the absence of any commercial or financial relationships that could be construed as a potential conflict of interest.

Copyright (C) 2015 Caldwell, Harenski, Harenski, Fede, Steele, Koenigs and Kiehl. This is an open-access article distributed under the terms of the Creative Commons Attribution License (CC BY). The use, distribution or reproduction in other forums is permitted, provided the original author(s) or licensor are credited and that the original publication in this journal is cited, in accordance with accepted academic practice. No use, distribution or reproduction is permitted which does not comply with these terms. 